THE PELAGIC COPEPODS OF THE IZU REGION, MIDDLE JAPAN SYSTEMATIC ACCOUNT III. -FAMILY AETIDEIDAE (PART 1)-

$\operatorname{AUTHOR}(S)$ :

Tanaka, Otohiko

CITATION:

Tanaka, Otohiko. THE PELAGIC COPEPODS OF THE IZU REGION, MIDDLE JAPAN

SYSTEMATIC ACCOUNT III. -FAMILY AETIDEIDAE (PART 1)-. PUBLICATIONS OF THE SETO MARINE BIOLOGICAL LABORATORY 1957, 6(1): 31-68

ISSUE DATE:

1957-06-30

URL:

http://hdl.handle.net/2433/174574

RIGHT: 


\title{
THE PELAGIC COPEPODS OF THE IZU REGION, MIDDLE JAPAN SYSTEMATIC ACCOUNT III. \\ FAMILY AETIDEIDAE (PART 1)
}

\author{
OTOHIKO TANAKA \\ Fisheries Department, Faculty of Agriculture, Kyushu University
}

With 18 Text-figures

\section{Family AETIDEIDAE}

Genus Aetideus BRADY, 1883

\begin{abstract}
Up to the present time four species of this genus have been recorded: Aetideus armatus (Boeck), A. giesbrechti (Cleve), A. bradyi A. Sc@Tt, and A. acutus Farran. The genus has the following characters: head and first thoracic segment are fused, and so are the fourth with the fifth; lateral corners of last thoracic segment produced into an acute spine on each side; abdomen 4-jointed in female; first antenna 23-jointed, joints 8 and 9 , joints 24 and 25 are fused; second antenna with endopodite about as long as exopodite; mandible has exopodite longer than endopodite; maxillae and maxillipede are of usual type; first leg with 3 -jointed exopodite and 1-jointed endopodite, outer marginal spine only on second and third joints of exopodite; second leg with 3-jointed exopodite and endopodite; third and fourth leg with 3-jointed exopodite and endopodite; fifth leg absent in female. Male resembles female in general appearance, differing from it in the absence of rostral spine, in the number of abdominal segment, and in the structure of fifth pair of legs.

G. O. Sars divided the genus in two; Aetideus and Euaetideus on the ground that the shape of rostral spine is different; to the latter genus belong A. giesbrechti, A. bradyi, and $A$. acutus.
\end{abstract}

\section{Aetideus armatus (BOECK)}

(Fig. 23, $a-i$ )

Aetideus armatus SARS, 1903, p. 25 ; ESTERLY, 1905, p. 154 ; A. SCOTT, 1909, p. 37 ; WolfEnden, 1911 , p. 209 ; WiTH, 1915 , p. 75 ; SARS, 1925, p. 41 ; FARRAN, 1926, p. 246 ; FARRAN, 1929, p. 228 ; SEWELL, 1929, p. 99 ; WILSON, 1932, p. 45 ; JESPERSEN, 1934, p. 52 ; FARRAN, 1936 , p. 87 ; MORI, 1937, p. 38 ; WILSON, 1950, p. 159 ; BRODSKY, 1950, p. 143.

Publ. Seto Mar. Biol. Lab., VI (1), 1957. (Article 3) 
Female. Length, $1.82 \mathrm{~mm}$ : cephalothorax, $1.43 \mathrm{~mm}$; abdomen, $0.39 \mathrm{~mm}$. In dorsal view cephalothorax moderately robust; frontal margin of head rounded, and has no median crest (fig. $a$ ). In lateral aspect, head is boldly arched (fig. $b$ ) ; rostrum consists of two rather slender spines, and has a knob at the middle of the base. Last thoracic segment ends in two acute spines which are more slender than those figured by previous authors.

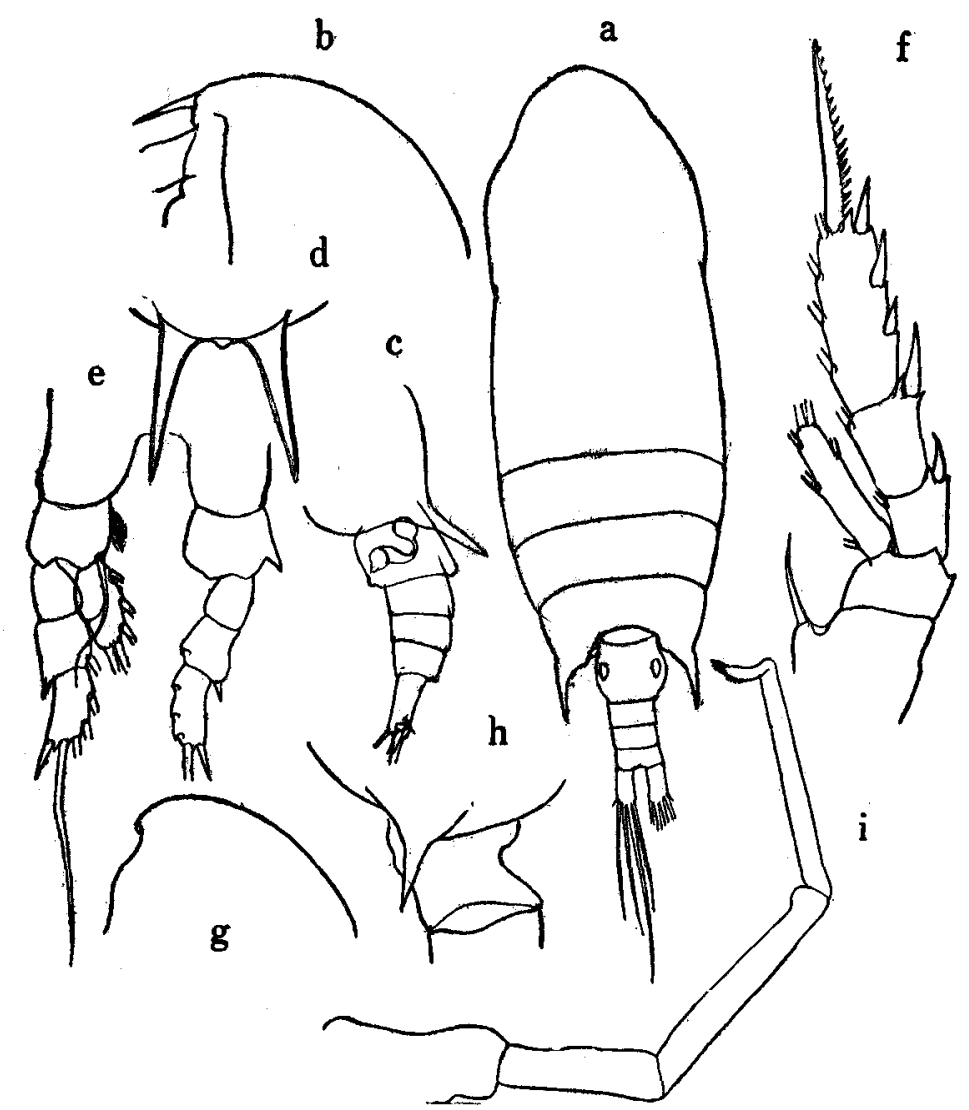

Fig. 23. Aetideus armatus (BoEcK).

$a$, Female : dorsal aspect ; $b$, head, lateral aspect; $c$, last thoracic segment and abdomen, lateral aspect; $d$, rostrum; $e, 1$ st leg ; $f, 2$ nd leg; $g$, Male: head, lateral aspect; $h$, last thoracic segment, lateral aspect; $i$, 5 th pair of legs.

Abdominal segments and furca are in the proportional lengths $35: 16: 14: 12: 23$ $=100$; genital segment wider than long; furcal rami 2-times as long as wide.

First antenna 23-jointed, extends to distal end of furca; joint 23 is as long as the 22nd; in A. ScotT's figure joint 23 is shorter than the 22nd. Second antenna has exopodite about as long as endopodite. Mandible has a slender second basal joint. 
First maxilla has 9 setae on outer lobe, 11 setae on exopodite, $6+3+4$ setae on endopodite, 5 setae on second basal joint. Second maxilla and maxillipede as figured by previous authors.

First leg has 3-jointed exopodite and 1-jointed endopodite; in the present specimen mounted right leg is of abnormal structure; second basal joint has an outer-edge spine as shown in the figure (fig. $e$ ). Second leg has 3 -jointed exopodite and 1 -jointed endopodite; outer edge spine of second exopoddite exceeds base of proximal spine of third joint; terminal spine of exopodite has 17 teeth (fig. $f$ ). Third and fourth legs have each 3-jointed exopodite and endopodite; terminal spine of exopodite of third leg has 17 teeth; that of fourth leg has 13 teeth on the left and 15 on the right leg.

Male. Length, $1.80 \mathrm{~mm}$ : cephalothorax, $1.32 \mathrm{~mm}$; abdomen, $0.48 \mathrm{~mm}$. In dorsal view male has general resemblance to female; but lateral spines of last thoracic segment shorter. Rostrum much reduced, and represented by only a small knob. Abdomen 5-segented, segments and furca in proportional lengths 16:23:23:21: $2: 15=100$; anal segment very short and almost concealed beneath the preceding; furcal rami about 2 -times as long as wide.

First antenna reaches back to middle of third abdominal segment; joints with following proportional lengths:

$$
\begin{array}{rrrcrrrcccccccc}
\text { Joint } & 1 & 2 & 3 & 4 & 5 & 6 & 7 & 8-9-10 & 11 & 12-13 & 14 & 15 & 16 & 17 \\
27 & 45 & 25 & 24 & 24 & 27 & 30 & 66 & 27 & 57 & 33 & 45 & 54 & 57 \\
18 & 19 & 20-21 & 22 & 23 & 24 & 25 & & & & & & \\
57 & 72 & 117 & 60 & 75 & 69 & 9=1000 ; & & & & &
\end{array}
$$

joints 3,9 and 14 have each a long seta; proximal joints have each well developed aesthetasks. Second antenna with exopodite about 1.2-times as long as endopodite.

Swimming legs as in female; end-spine of exopodite of second leg has 26 teeth, and that of third leg has 26 teeth. Right fifth leg rudimentary; left leg slender; distal joint short, and furnished with hairs along inner margin; apex of the joint carries four small spines (fig. $i$ ).

Occurrence. One adult female and male from Sagami in July, and one male from Suruga, December 1937, from the depth $1000 \mathrm{~m}$ to the surface.

Distribution. It is widely distributed in the North Atlantic, Pacific, Indian, Malayan and Chinese seas, also in the Great Barrier Reef region.

\section{Aetideus giesbrechti (CLEVE)}

Aetideus armatus Giesbrecht, 1892, p. 213; Aetideus giesbrechti A. ScotT, 1909, p. 36; WOLFENDEN, 1911, p. 209; Euaetideus giesbrechti G. O. SARS, 1925, p. 42; Aetideus giesbrechti FARRAN, 1926, p. 247; FARRAN, 1929, p. 228; FARRAN, 1936, p. 87 ; MoRI, 1937, p. 38, pl. 16 .

Female. Length, $1.98 \mathrm{~mm}$ : cephalothorax, $1.59 \mathrm{~mm}$; abdomen, $0.39 \mathrm{~mm}$.

Remarks. A. giesbrechti is distinguished from $A$. acutus by the shape of head 
and lower crest. The "Siboga" specimen measured $2.1 \mathrm{~mm}$ in female; Farran's specimen from New Zealand, $1.92-1.98 \mathrm{~mm}$. The specimen from Izu has longer furca. WOLFENDEN's specimen is not evenly rounded on the frontal margin of the head.

Occurrence. One adult female from the surface layer of Sagami Bay, in December 1935.

Distribution. It has been recorded from the Indian Ocean, Malay Archipelago and Gulf of Guinea. The species appears to be a warm-water inhabitant.

\section{Aetideus bradyi A. ScotT}

(Fig. 24, $a-i$ )

Aetideus bradyi A. ScotT, 1909, p. 38, pl. 5.

Female. Length, $1.46 \mathrm{~mm}$ : cephalothorax, $1.14 \mathrm{~mm}$; abdomen, $0.32 \mathrm{~mm}$. In dorsal view frontal margin of head is constricted by the base of rostrum (fig. a.). In lateral view crest well marked; forehead is highly chitinised (fig. b.). Rostrum short and strong, with divergent points; knob-like processes of inner side of the wide base are observed in trace (fig. $d$ ). Wing-like processes of last thoracic segment reach back to distal margin of second abdominal segment (fig. $c$ ).

Proportional lengths of abdominal segments and furca: $35: 18: 12: 15: 20=100$. Furcal rami two times as long as wide; appendicular seta long (fig. $e$ ).

First antenna reaches back to distal margin of fourth abdominal segment; proportional lengths of joints are:

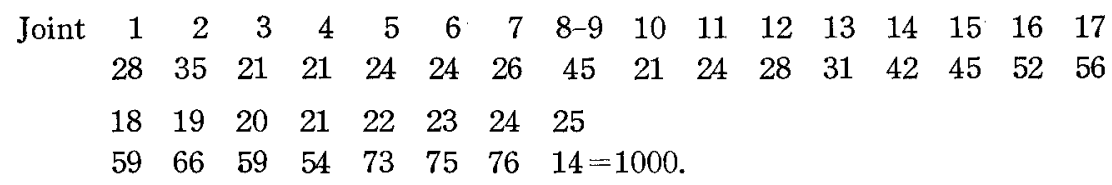

Mouth parts and swimming legs have no interesting features; the number of teeth on terminal spine of exopodite of second and third legs are 15 and 13 respectively.

Male. Length, $1.40 \mathrm{~mm}$ : cephalothorax $1.10 \mathrm{~mm} ; 0.39 \mathrm{~mm}$. The specimen resembles male of $A$. armatus (fig, $f$ ). Forehead slightly chitinised. Rostrum is represented by a small knob-like projection when viewed from the lateral (fig. $h$ ). Lateral corners of last thoracic segment produced on each side into a strong spine with a basal thickening (fig. $g$ ).

Abdomen 5-segmented, segments and furca in proportional lengths 19:22:19: $19: 4: 17=100$. Furcal rami 1.7 times as long as wide.

First antenna 25-jointed, reaches back to distal margin of second abdominal segment; joints are in the following proportional lengths:

$\begin{array}{rrrrrrrrccccccc}\text { Joint } & 1 & 2 & 3 & 4 & 5 & 6 & 7 & 8-9-10 & 11 & 12-13 & 14 & 15 & 16 & 17 \\ 28 & 33 & 20 & 20 & 24 & 24 & 28 & 65 & 24 & 61 & 37 & 45 & 57 & 61 \\ 18 & 19 & 20-21 & 22 & 23 & 24 & 25 & & & & & & \\ 61 & 69 & 107 & 73 & 77 & 77 & 8=1000 ; & & & & & \end{array}$


these proportional lengths are quite different from those of $A$. armatus. Second antenna with exopodite about 1.1-times as long as endopodite. Outer lobe of first maxilla has 5 long setae; exopodite with 10 setae. Maxillipede has first and second basal joints and endopodite in following proportional lengths $30: 30: 16$.

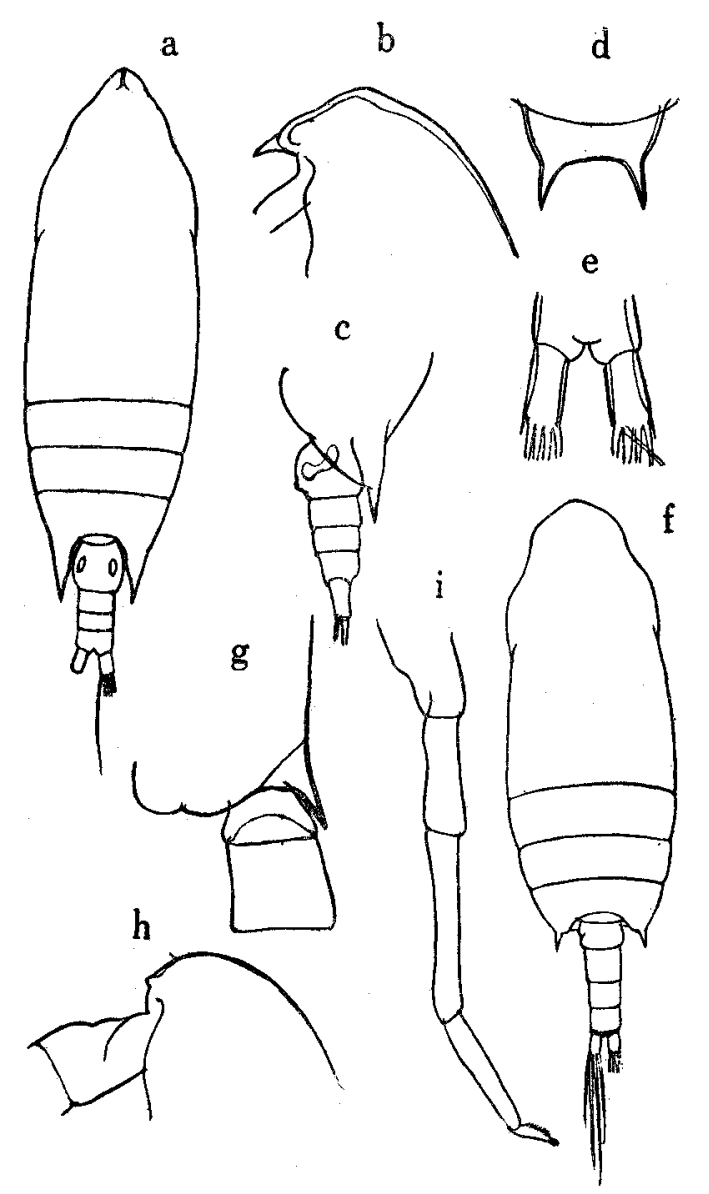

Fig. 24. Aetideus bradyi A. Scotr.

$a$, Female: dorsal aspect; $b$, head, lateral aspect ; $c$, last thoracic segment and abdomen, lateral aspect; $d$, rostrum; $e$, anal segment and furca; $f$, Male: dorsal aspect; $g$, last thoracic segment, lateral aspect; $h$, head, lateral aspect; $i, 5$ th pair of legs.

Swimming legs do not show any specific character. Number of teeth on terminal spine of exopodite of second to fourth legs are 20,19 , and 16 respectively. In fifth pair of legs right one is reduced; left one is long and slender as in A. armatus (fig. $i$ ).

Remarks. The present male specimen can be distinguished from $A$. armatus in the followings: much smaller size; proportional lengths of abdominal segments, and 
joints of 1st antenna. Immature male specimen, measured $1.36 \mathrm{~mm}$, has left fifth leg composed of three joints; right leg reduced. Shape of head resembles that of the adult female.

Occurrence. One adult female from the surface layer of Sagami in winter 1935 and an adult female and an immature male in a vertical hauls from the depth $1260 \mathrm{~m}$ to the surface in Suruga Bay, Dec. 1937,

Distribution. The species has been recorded only from the Malayan region. The species appears to be distributed in the warm regions of the Indo-Pacific.

\section{Aetideus acutus FARRAN}

(Fig. 25, $a-g$ )

Aetideus acutus FARran, 1929, p. 228, fig. 5 ; FARRAN, 1936, p. 87.

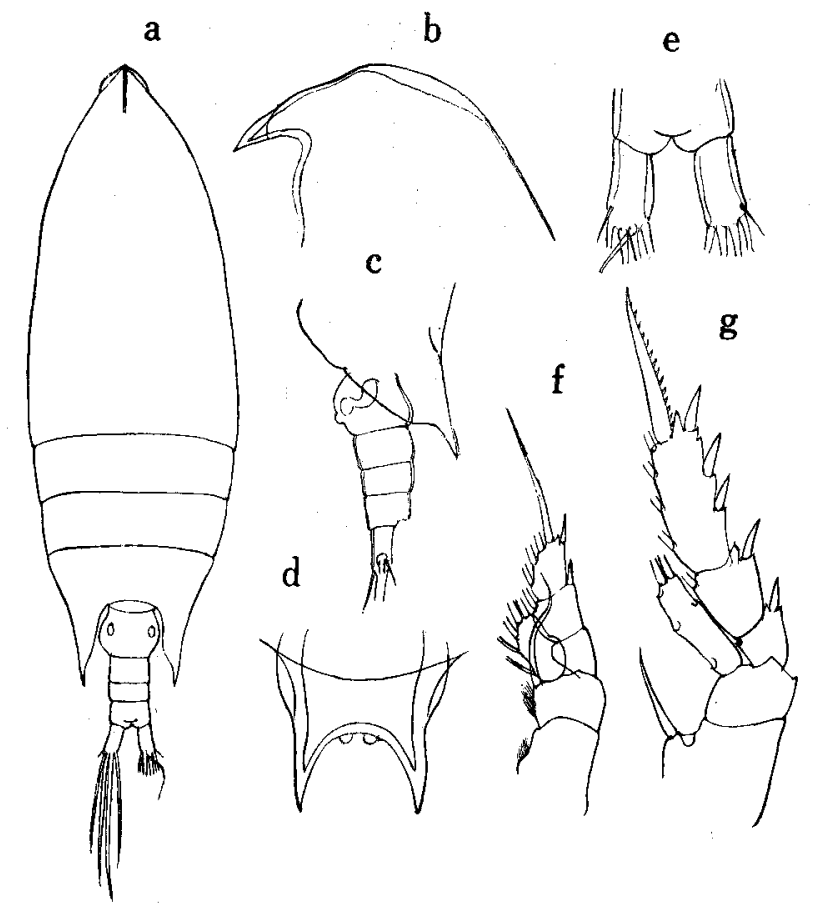

Fig. 25. Aetideus acutus FARRAN.

$a$, Female: dorsal aspect; $b$, head, lateral aspect; $c$, last thoracic segment and abdomen, lateral aspect; $d$, rostrum; $e$, anal segment and furca; $f, 1$ st leg; $g$, 2nd leg.

Female. Length, $1.66 \mathrm{~mm}$. Abdomen is contained 3.6-times in the length of cephalothorax. In dorsal view head contracts gradually to a blunt point and the frontal margin is constricted by wide base of rostrum (fig. a). In lateral view frontal margin of head has a well-marked chitinous crest which is slightly raised at the apex, 
but it is not so strongly arched as described and figured by Farran (fig. $b$ ). Rostrum is large and strongly chitinised with points directing rather straight, and has two knobs at its base (fig. d). Last thoracic segment well chitinised, and produced into strong points reaching to the middle of third abdominal segment (fig. $c$ ).

Proportional lengths of abdominal segments and furca are $34: 18: 13: 13: 22=100$; the segments and furca well chitinised. Furcal rami 2 -times as long as wide (fig. $d$ ). Mouth parts as those of Aetideus giesbrechti.

First antenna exceeds slightly distal end of furca; the joints are in proportional lengths:

$\begin{array}{rrrrrrrrrrrrrrrrr}\text { Joint } & 1 & 2 & 3 & 4 & 5 & 6 & 7 & 8-9 & 10 & 11 & 12 & 13 & 14 & 15 & 16 & 17 \\ 30 & 57 & 21 & 21 & 24 & 24 & 27 & 45 & 20 & 24 & 24 & 33 & 38 & 45 & 54 & 57 \\ 18 & 19 & 20 & 21 & 22 & 23 & 24 & 25 & & & & & & & & \\ 57 & 63 & 57 & 54 & 68 & 71 & 74 & 15=1000 . & & & & & & \end{array}$

Number of serration on terminal spine of exopodite of second to fourth legs are 15, 16 and 14 respectively. First and second legs as shown in the figures (fig. $f, g$ ).

Remarks. The species comes very near to $A$. giesbrechti, but differs from it in the shape of forehead both in dorsal and lateral aspects, in the proportional lengths of abdominal segments and furca, and also in the proportional lengths of joints of first antenna. The crest in lateral view is less prominent than that of $A$. bradyi.

Occurrence. The species is rather common both in the surface and deep waters.

Distribution. The species has been recorded from New Zealand and the Great Barrier Reef.

\section{Genus Aetideopsis G. O. Sars, 1903}

From the Malayan region only one species of this genus has, up to the present time, been reported: Aetideopsis multiserrata (WolfENDEN) (=Aetideopsis rostrata A. ScotT). I have found in the collection the same species and other two species which appear to be yet undescribed. The genus differs from Aetideus in the following: head and first thoracic segment completely or incompletely fused; last thoracic segment separates from the fourth; first antenna 24-jointed, joints 8 and 9 are fused; mouth parts as in Aetideus; first leg has an outer edge-spine on first joint of exopodite; first basal joint is furnished with spinules on the outer margin, and bristles on the inner margin; second leg has 2 jointed endopodite, first basal joint is furnished with groups of spinules on the outer proximal margin. Fifth leg absent in female. Male resembles female in general appearance; fifth pair of legs are of about equal lengths on each side with three free joints of exopodite attached to the 2 -jointed basals; the endopodite rudimentary.

\section{Aetideopsis multiserrata (WOLFENDEN)}

(Fig. 26, $a-m$ )

Faroella multiserrata WOLFENDEN, 1904, p. 117; FARRAN, 1908, p. 29; Aetideopsis rostrata A. SCOTT, 1909, p. 81 ; Chiridius nasitus WITH, 1915, p. 81; Aetideopsis multiserrata SARS, 1925, p. 43 ; Chiridius multiserrata FARRAN, 1926, p. 248 ; Aetideopsis multiserrata JESPERSEN, 1934, p. 53; BRODSKY, 1950, p. 146. 
Female. Length, $3.13 \mathrm{~mm}$ : cephalothorax, $2.38 \mathrm{~mm}$; abdomen, $0.75 \mathrm{~mm}$; so abdomen is contained about 3.2-times in length of cephalothorax. Body slender; the greatest width is about one-third the length of cephalothorax. Last two thoracic segments are separate. Lateral corners of last thoracic segment produced into a strong spine on each side, reaching the middle of genital segment (fig. $a, b$ ). Rostrum highly chitinised and very prominent. The shape in lateral view differs somewhat from the figure given by SARS or A. SCOTT; it directs anteriorly, hollowing at base; external margin of rostrum are not so concave, as figured by A. ScotT (fig. $f$ ).

Abdomen 4-segmented, segments and furca are in proportional lengths, 35:24: $17: 10: 14=100$. Genital segment produced moderately below (fig. $c$ ). Furcal rami about as long as wide; furcal setae slender (fig. $e$ ).

First antenna reaches back to distal margin of second abdominal segment; proportional lengths of joints are as follows:

$$
\begin{array}{rrrrrrrrrrrrrrrrr}
\text { Joint } & 1 & 2 & 3 & 4 & \mathbf{5} & \mathbf{6} & \mathbf{7} & 8-9 & 10 & 11 & 12 & 13 & 14 & 15 & 16 & 17 \\
& 35 & 63 & 29 & 24 & 29 & 29 & 31 & 59 & 29 & 29 & 29 & 31 & 38 & 42 & 45 & 45 \\
& 18 & 19 & 20 & 21 & 22 & 23 & 24 & 25 & & & & & & & & \\
45 & 66 & 70 & 45 & 38 & 66 & 63 & 20=1000 ; & & & & & &
\end{array}
$$

posterior seta of 23rd joint extends beyond distal margin of the 25th. Second antenna with exopodite about 1.3-times as long as endopodite. Mandible shows no characteristic features. Outer lobe of 1 st maxilla with 8 setae, exopodite with 10 setae. Second maxilla and maxillipede as figured by A. ScotT.

First leg has 3-jointed exopodite and 1-jointed endopodite; joints of exopodite are broad; first basal joint carries a group of spinules on the outer margin about middle (fig. $g$ ). Terminal spine of second to fourth legs have 40,36 , and 40 teeth respectively. Second leg as shown in the figure.

Male. Length, $3.04 \mathrm{~mm}$ : cephalothorax, $2.25 \mathrm{~mm}$; abdomen, $0.79 \mathrm{~mm}$. Head fused with first thoracic segment (fig. $j$ ). Line of fusion between fourth and fifth thoracic segments scarcely visible in dorsal aspect (fig. $i$ ). Base of lateral process of last thoracic segment moderately inflated (fig. $l$ ). Branches of rostrum closely set together.

Abdomen 5-segmented, segments and furca in proportional length $16: 34: 23: 16$ : $1: 10=100$. Furcal rami 1.4-times as long as wide. Second to fourth segments are fringed with fine teeth on the distal margin.

First antenna extends to distal end of second thoracic segment; joints are in proportional lengths:

$$
\begin{array}{rrrrrrrccccccccc}
\text { Joint } & 1 & 2 & 3 & 4 & 5 & 6 & 7 & 8-9-10 & 11 & 12 & 13 & 14 & 15 & 16 & 17 \\
& 42 & 61 & 28 & 28 & 33 & 33 & 38 & 113 & 38 & 38 & 38 & 38 & 42 & 42 & 39 \\
19 & 20 & 21 & 22 & 23 & 24 & 25 & & & & & & & & \\
42 & 52 & 52 & 52 & 52 & 46 & 14=1000 . & & & & & & &
\end{array}
$$

Second antenna with exopodite little longer than endopodite; first basal joint has rows of hairs on the posterior surface. Mandible not characteristic. In first maxilla first 

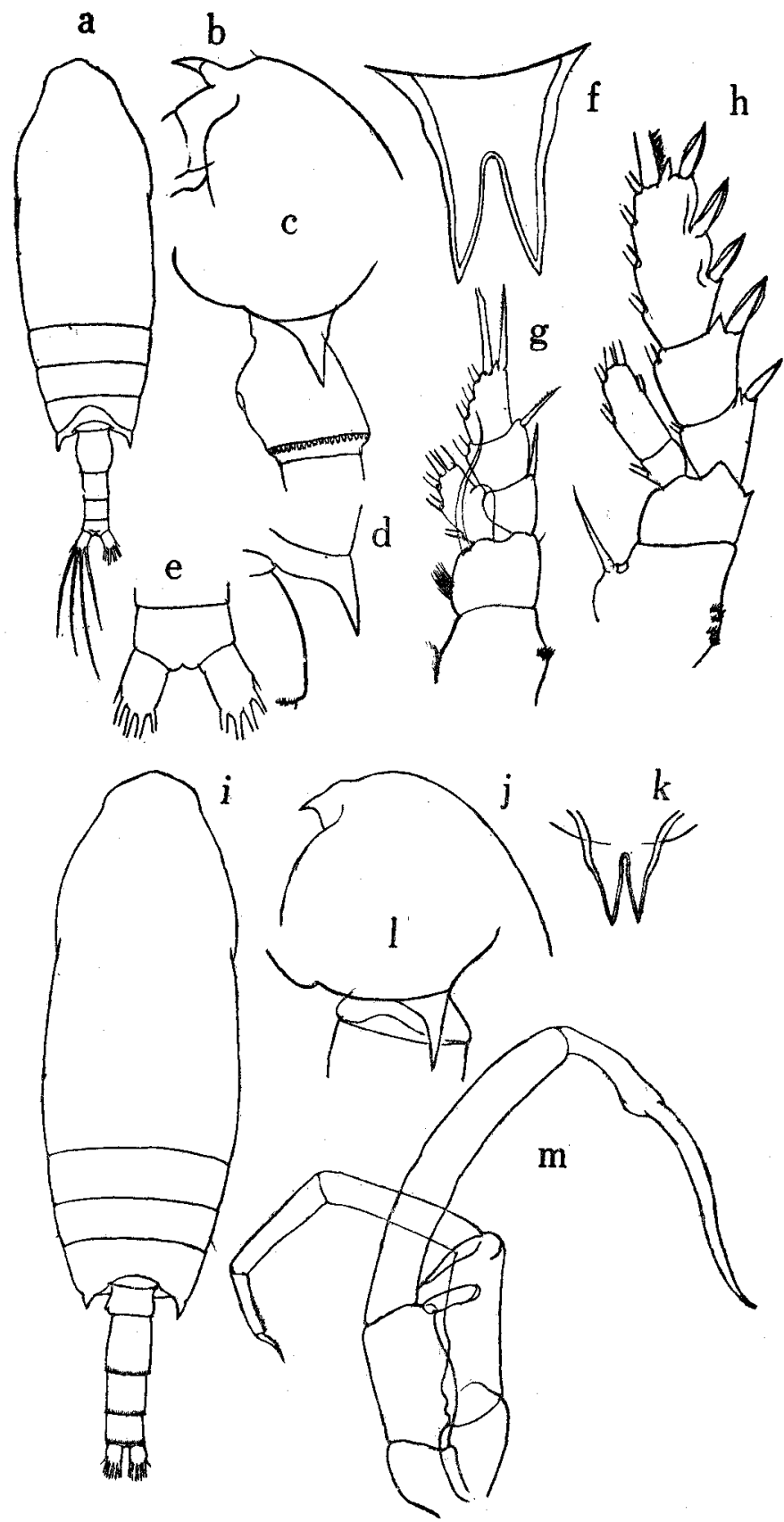

Fig. 26. Aetideopsis multiserrata WOLFENDEN.

$a$, Female : dorsal aspect; $b$, head, lateral aspect; $c$, last thoracic segment and genital segment, lateral aspect; $d$, last thoracic segment, dorsal aspect; $e$, anal segment and furca, dorsal aspect; $f$, rostrum; $g, 1$ st leg; $h$, 2nd leg; $i$, Male: dorsal aspect; $j$, head, lateral aspect; $k$, rostrum; $l$, last thoracic segment, lateral aspect; $m$, 5 th pair of legs. 
outer lobe has 6 long and 3 short setae, and a rounded swelling on outer margin when viewed in posterior aspect; spinulation of various parts as follows: exopodite, 9 setae; endopodite, 11 setae; second basal joint, 4 setae; third inner lobe, 3 setae; first and second inner lobe have each rudimentary sensory setae. Maxillipede has a slender second basal joint.

In first leg outer-edge spine of joints of exopodite rather short when compared with those of adult female or immature male. Second leg with 2 -jointed endopodite; terminal spine of exopodite with 40 teeth; first basal joint with fine spinules on the outer margin. Third and fourth legs broken off. Fifth pair of legs resemble those of Aetideopsis minor Wolfenden (fig. $m$ ).

Remarks. Shape of rostrum, lateral process of last thoracic segment, and proportional lengths of joints of first antenna distinguish the present specimen from Aetideopsis minor Wolfenden. Vervoort (1950) described a new species, Aetideopsis trichechus. He is convinced that his species is identical with $A$. rostrata A. ScotT. But his specimen differs from the latter in the shape of rostrum, and in the proportional lengths of outer-edge spine of joints of exopodite of first leg.

Occurrence. Three adult females and one male from Suruga, July 1937; fourty three females and three males from Sagami, November 1937, from the depth $1000 \mathrm{~m}$ to the surface.

Distribution. Recorded from the North Atlantic and Malayan region.

\section{Aetideopsis divergens sp. nov.}

(Fig. 27, $a-j$ )

Female. Length, $3.01 \mathrm{~mm}$ : cephalothorax, $2.35 \mathrm{~mm}$; abdomen, $0.66 \mathrm{~mm}$; so abdomen is contained 3.5-times in the length of cephalothorax. Cephalothorax about 2.6-times as long as it is wide at first thoracic segment. Posterior spines of last thoracic segment wider but shorter when compared with those of the preceding species. Articular membrane between head and first thoracic segment is observed both in dorsal and lateral aspects. Integuments finely granulated (fig. $a, b, c$ ). Rostrum stout, bifurcate and strongly divergent (fig. $d$ ).

Abdomen 4-segmented, segments and furca with proportional lengths $38: 19: 16$ : $11: 16=100$. Genital segment about as long as wide. Furcal rami little longer than wide $(6: 5)$, and slightly divergent.

First antenna 24-jointed, extends to distal margin of third abdominal segment: joints with following proportional lengths:

$$
\begin{array}{rrrrrrrrrrrrrrrrr}
\text { Joint } & 1 & 2 & 3 & 4 & 5 & 6 & 7 & 8-9 & 10 & 11 & 12 & 13 & 14 & 15 & 16 & 17 \\
& 34 & 60 & 24 & 30 & 27 & 27 & 30 & 60 & 27 & 27 & 27 & 37 & 37 & 47 & 47 & 50 \\
& 18 & 19 & 20 & 21 & 22 & 23 & 24 & 25 & & & & & & & & \\
43 & 63 & 70 & 43 & 53 & 63 & 63 & 20=1000 . & & & & & &
\end{array}
$$


Second antenna with exopodite about 1.3-times as long as endopodite. Mandible, maxilla, and maxillipede as those of $A$. rostrata SARs.

In first leg outer edge spines of exopodite long and slender (fig. $e$ ). Joints of endopodite of second leg are incompletely separate; articular membrane clearly seen on the posterior surface. Terminal spines of second to fourth legs have 58, 45, and 40 teeth respectively; the teeth are partially fused on its basal part by a sort of lamella.

Male. length, $3.13 \mathrm{~mm}$ : cephalothorax, $2.25 \mathrm{~mm}$; abdomen $0.98 \mathrm{~mm}$. Body oblong ovate. Cephalothorax 2.5-times as long as it is wide at first thoracic segment. Head

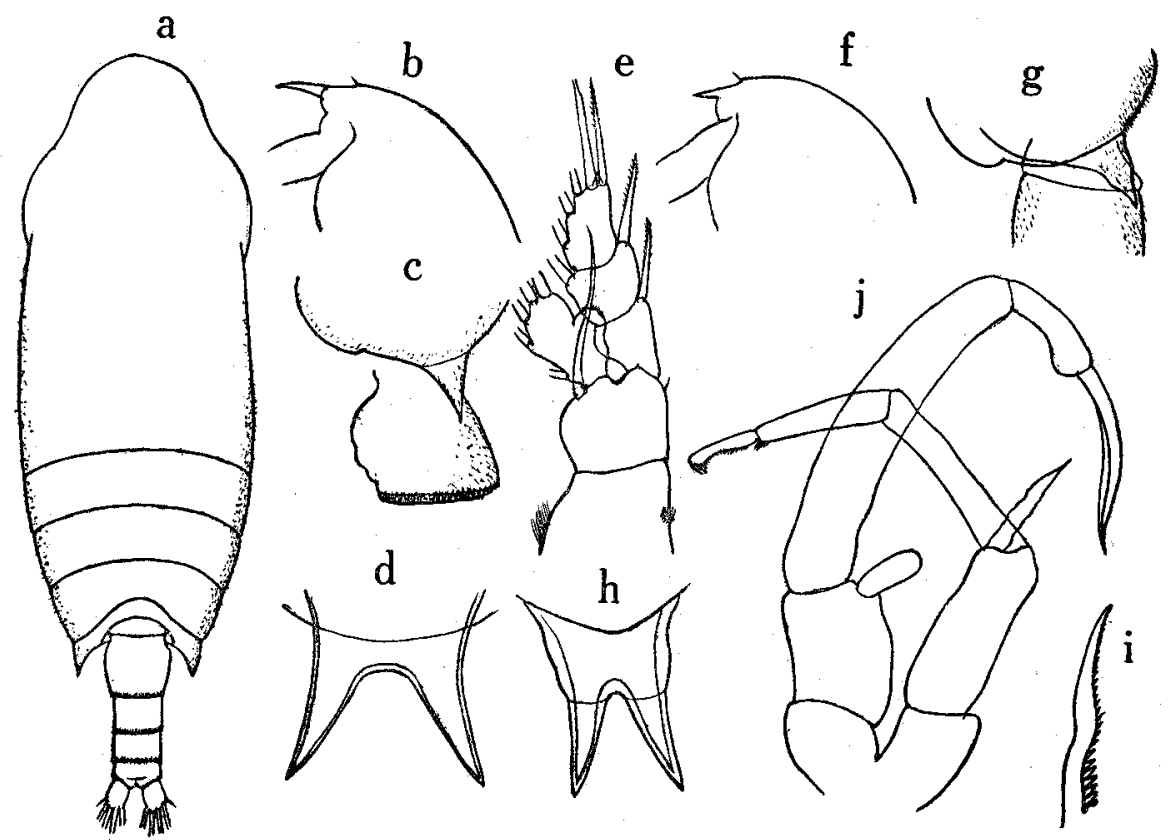

Fig. 27, Aetideopsis divergens sp. nov.

$a$, Female : dorsal aspect; $b$, head, lateral aspect; $c$, last thoracic segment and genital segment, lateral aspect; $d$, rostrum; $e, 1$ st leg ; $f$, Male : head, lateral aspect ; $g$, last thoracic segment, lateral aspect ; $h$, rostrum ; $i$, terminal spine of exopodite of 2 nd leg; $j, 5$ th pair of legs.

and first thoracic segment completely fused; fourth and fifth thoracic segments are partially fused; the line of fusion faintly visible in dorsal aspect, thoracic segments finely granulated (fig. $f, g$ ). Rostrum divergent, pointing forwards (fig. $h$ ).

Abdomen 5-segmented, proportional lengths of segments and furca are 12:31: $25: 18: 2: 12=100$. Anal segment concealed beneath the foregoing. Furcal rami about as long as wide.

First antenna reaches back to distal margin of second thoracic segment; proportional lengths of joints as follows: 


$$
\begin{array}{rrrrrrrccccccccc}
\text { Joint } & 1 & 2 & 3 & 4 & 5 & 6 & 7 & 8-9-10 & 11 & 12 & 13 & 14 & 15 & 16 & 17 \\
40 & 70 & 30 & 30 & 34 & 34 & 34 & 104 & 34 & 30 & 35 & 35 & 40 & 40 & 40 \\
18 & 19 & 20 & 21 & 22 & 23 & 24 & 25 & & & & & & & \\
45 & 60 & 60 & 45 & 50 & 50 & 45 & 15=1000 . & & & & & &
\end{array}
$$

Second antenna strong; exopodite about as long as endopodite. Mandible and second maxilla reduced. Maxillipede with long basal joints; fourth joint of endopodite produced anteriorly.

In first leg outer edge spine of exopodite rather short; inner margin of second basal joint smooth. Second leg with 48 teeth on the terminal spine of exopodite; the terminal spine is deformed as shown in the figure (fig. $i$ ). Third leg missing. Fourth leg has 42 teeth on terminal spine of exopodite. Fifth pair of legs as in Chiridius armatus (BoEcK); endopodite rudimentary (fig. $j$ ).

Immature male measured $2.7 \mathrm{~mm}$. First antenna extends to distal margin of third abdominal segment. First leg resembles that of the adult female.

Remarks. The specimens agree with Aetideopsis minor Wolfenden, except for divergent rostrum and somewhat short furca. A. minor has the furca which is about 2-times as long as wide; FARRAN's specimen of the same species $(2.92-3.25 \mathrm{~mm}$ ) from the Antarctic has furcal rami 1.5-times as long as wide. Endopodite of second leg is, according to WOLFENDEN, 3-jointed, but it is 2-jointed in FARran's specimen. A. minor WOLFENDEN (Chiridius minor FARRAN) has been recorded only from the Antarctic. The present specimens were collected in the vertical hauls $1000-800 \mathrm{~m}$, $1000-600 \mathrm{~m}, 200-0 \mathrm{~m}$, and $100-0 \mathrm{~m}$. It is unreasonable that the Antarctic species has so wide a distribution in the upper layers of the North Pacific. Shape of rostrum and structure of furcal rami are different from those of the Antarctic specimen. The present specimen differs from either of $A$. pacifica and A. divaricata described by Esterly.

Occurrence. Six adult females and one male in all from deep waters of both Sagami and Suraga.

\section{Aetideopsis cristata sp. nov.}

(Fig. 28, $a-m$ )

Female. Length, $3.84 \mathrm{~mm}$ : cephalothorax, $2.94 \mathrm{~mm}$; abdomen, $0.90 \mathrm{~mm}$; so abdomen is contained 3.26-times in length of cephalothorax. Head with chitinised median crest, separates from 1st thoracic segment. Last two thoracic segments separate; last thoracic segment produced posteriorly into spines which extend to more than twothirds of genital segment. Integument finely granulated (fig. $a, b, c$ ). Rostrum very strong, with a wide base; rami straight and parallel (fig. $d$ ).

Abdomen 4-segmented, segments and furca with proportional lengths: $25: 23: 19$ : $14: 19=1000$. Genital segment produced below. Furcal rami $1.3-$ times as long as wide.

First antenna extends to distal margin of 3rd abdominal segment; proportional lengths of joints as follows: 

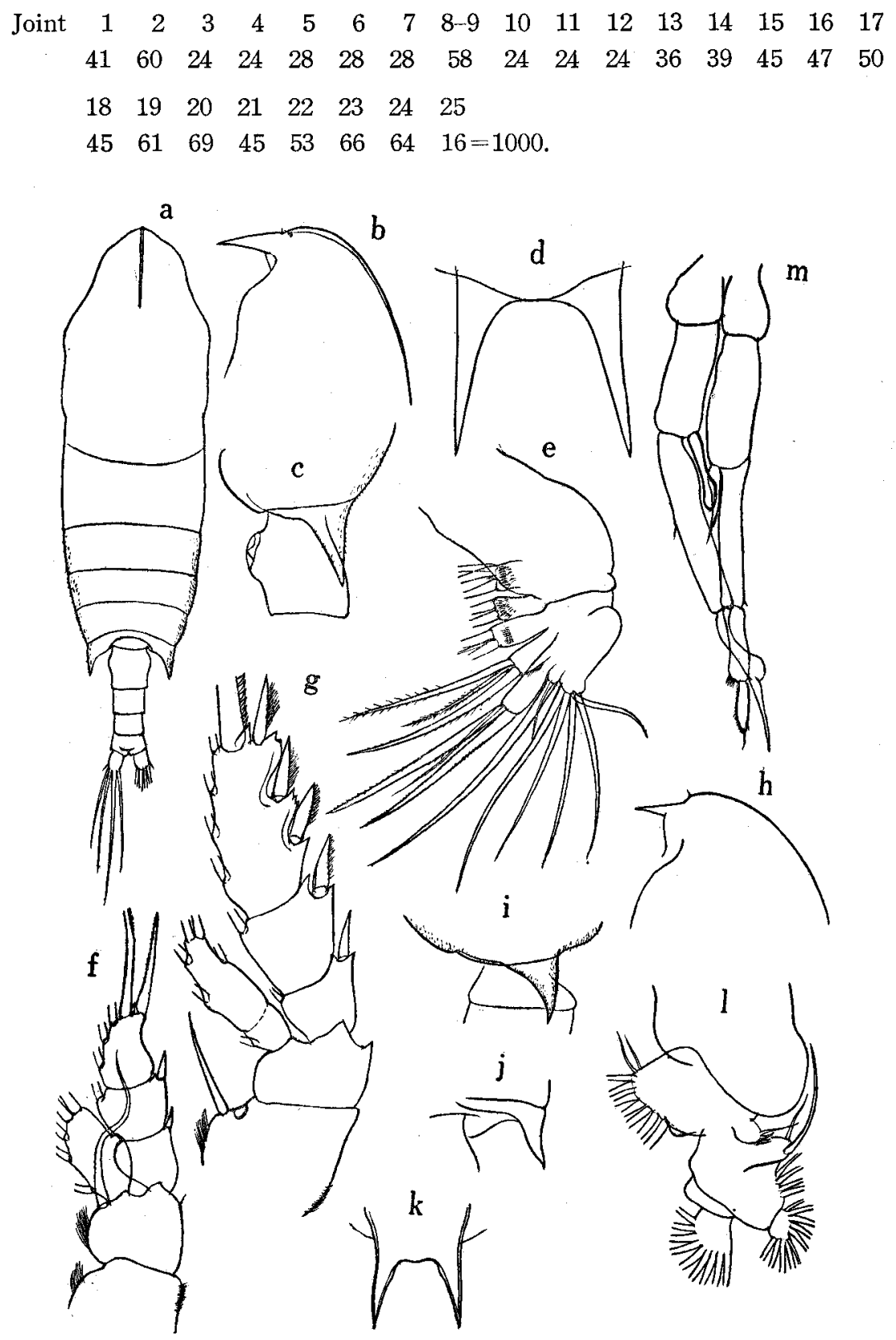

Fig. 28. Aetideopsis cristata sp. nov.

$a$, Female: dorsal aspect; $b$, head, lateral aspect; $c$, last thoracic segment and genital segment, lateral aspect ; $d$, rostrum ; $e, 2$ nd maxilla ; $f$, 1st leg ; $g$, 2nd leg; $h$, Male: head, lateral aspect; $i$, last thoracic segment; lateral aspect; $j$, last thoracic segment, dorsal aspect; $k$, rostrum ; $l$, 1st maxilla ; $m, 5$ th pair of legs. 
Second antenna with exopodite about 1.2-times as long as endopodite. First maxilla with 7 long and 2 short setae on first outer lobe; second outer lobe without seta; exopodite with 10 setae; second basal with 5 setae; endopodite with $4+3+6$ setae; first inner lobe with 14 setae; second inner lobe with 5 setae; third lobe with 4 setae. Second maxilla and maxillipede as those of the preceding species (fig. $e$ ).

In first leg outer edge spine of first and second joints of exopodite short, not reaching the middle of the next (fig. $f$ ). Second leg has articular membrane between first and second joints on anterior surface of endopodite (fig. $g$ ). Terminal spine of exopodite of second to fourth legs have 27,32 and 40 teeth respectively.

Male. Length, $3.25 \mathrm{~mm}$ : cephalothorax $2.55 \mathrm{~mm}$; abdomen, $0.97 \mathrm{~mm}$; so abdomen is contained 2.7-times in length of cephalothorax. Head and first thoracic segment completely fused; fourth and fifth thoracic segments incompletely articulated. Posterior margin of last thoracic segment produced into spines extending to distal margin of first abdominal segment (fig. $h$ ). Integument finely granulated. Rostrum strong, slightly divergent, and has a wide base (fig. $k$ ).

Abdominal segments and furca with proportional lengths 12:30:24:19:2:13 $=100$; second to fourth segments are fringed with fine teeth on the distal margin. Furcal rami 1.4-times as long as wide.

First antenna extends to distal margin of second thoracic segment; proportional lengths of joints are as follows:

$$
\begin{array}{rrrrrrrccccccccc}
\text { Joint } & 1 & 2 & 3 & 4 & 5 & 6 & 7 & 8-9-10 & 11 & 12 & 13 & 14 & 15 & 16 & 17 \\
& 54 & 54 & 31 & 31 & 31 & 36 & 36 & 72 & 31 & 32 & 41 & 36 & 45 & 45 & 45 \\
& 18 & 19 & 20 & 21 & 22 & 23 & 24 & 25 & & & & & & & \\
45 & 58 & 58 & 45 & 49 & 58 & 54 & 13=1000 ; & & & & & &
\end{array}
$$

joints 9 and 10 are fused on the posterior margin. Second antenna with exopodite about as long as endopodite. Mandible with a rounded second basal joint; exopodite about as long as endopodite. Maxilla with 9 setae on outer lobe; 9 setae on exopodite (fig. $l$ ). Second maxilla much reduced. Second basal joint of maxillipede a little longer than first.

First to fourth swimming legs as in the female. Terminal spine of exopodite of second to fourth legs with 31,34 and 36 teeth respectively.

Fifth pair of legs as those of Chiridius armatus (BoECK) figured by SARS (fig. $m$ ).

Remarks. The present specimen differs from the other member of the genus in the followings: shape of rostrum; forehead with median crest; short outer edge spine of first and second joints of exopodite of first leg.

Occurrence. 118 females and 4 males from Sagami in the vertical hauls from the depth $1000 \mathrm{~m}$ to the surface, Nov. 1937.

Genus Undinopsis G. O. SARS, 1884

(Bradyidius GIESBRECHT) 
The genus comprises, at present three species, Undinopsis bradyi SARS (=Bradyidius armatus GIESBRECHT), U. tropicus WOLFENDEN and U. stimilis SARS. A single specimen belonging to the genus was found in the collection, which appears to be different from those hitherto been described. The generic characters are as follows: head fused with first thoracic segment; fourth and fifth thoracic segments are fused; rostrum terminates into strong bifurcate points; last thoracic segment ends in acute expansions; abdomen of female 4-jointed; first antenna 24-jointed; mouth parts as those of Aetideus; first leg with 3-jointed exopodite and 1-jointed endopodite; joints of exopodite bears each an outer edge spine; second leg with 3 -jointed exopodite and 2 -jointed endopodite; third and fourth legs with 3 -jointed exopodite and endopodite; endopodite of second to fourth legs are furnished with groups of minute spinules. Fifth leg absent in female. SARS recorded the occurrence of Undinopsis bradyi from the Norwegian Sea. Wolfenden, A. ScotT, and FARRAN recorded the tropical species $U$. tropicus Wolfenden from the Maldive Archipelago, Malay Archipelago and Great Barrier Reef area respectively. From Japanese waters MoRI reported $U$. bradyi under the name Bradyidius armatus (BRADY). It is said that $U$. bradyi and $U$. tropicus differ only in size and in minute points of structure.

\section{Undinopsis angustus sp. nov.}

(Fig. 29, $a-i$ )

Male. Length, $1.37 \mathrm{~mm}$ : cephalothorax, $1.03 \mathrm{~mm}$; abdomen, $0.34 \mathrm{~mm}$; so abdomen is contained 3-times in the length of cephalothorax. Cephalothorax moderately robust; the greatest width less than half the length of cephalothorax. Head fused with first thoracic segment, so are the fourth with the fifth (fig. a). Posterior margin of last thoracic segment produced into acute spines extending beyond distal margin of first abdominal segment (fig. c). Rostrum strong, curved somewhat posteriorly at the apex (fig. $b$ ).

Abdomen 5 -segmented, segments and furca with proportional length $14: 32: 19$ : $19: 3: 13=100$; second to fourth segments are fringed with fine teeth on the distal margin. Furcal rami 1.3-times as long as wide.

First antenna extends to distal margin of second abdominal segment; joints are in the following proportional length:

$\begin{array}{rrrrrrrcccccccc}\text { Joint } & 1 & 2 & 3 & 4 & 5 & 6 & 7 & 8-9-10 & 11 & 12-13 & 14 & 15 & 16 & 17 \\ 24 & 36 & 20 & 20 & 24 & 28 & 32 & 82 & 28 & 73 & 41 & 49 & 49 & 53 \\ 18 & 19 & 20 & 21 & 22 & 23 & 24 & 25 & & & & & & \\ 56 & 65 & 61 & 56 & 65 & 65 & 61 & 12=1000 ; & & & & & \end{array}$

joints 20 and 21 are fused on the right. Second antenna with exopodite about as long as endopodite (fig. $e$ ). Second maxilla much reduced. Maxillipede has a large second joint of endopodite. 
First leg has on first joint of exopodite a short outer edge spine; third joint of exopodite has also a short outer edge spine; first basal joint with fine spinules on the outer margin (fig. $f$ ). Second leg has 2-jointed endopodite; second joint of endopodite has three groups of spinules on the posterior surface; terminal spine of the exopodite has 24 teeth on the left, 22 teeth on the right (fig. $g$ ). Third and fourth legs with 3 -jointed endopodite; second and third joints of endopodite are

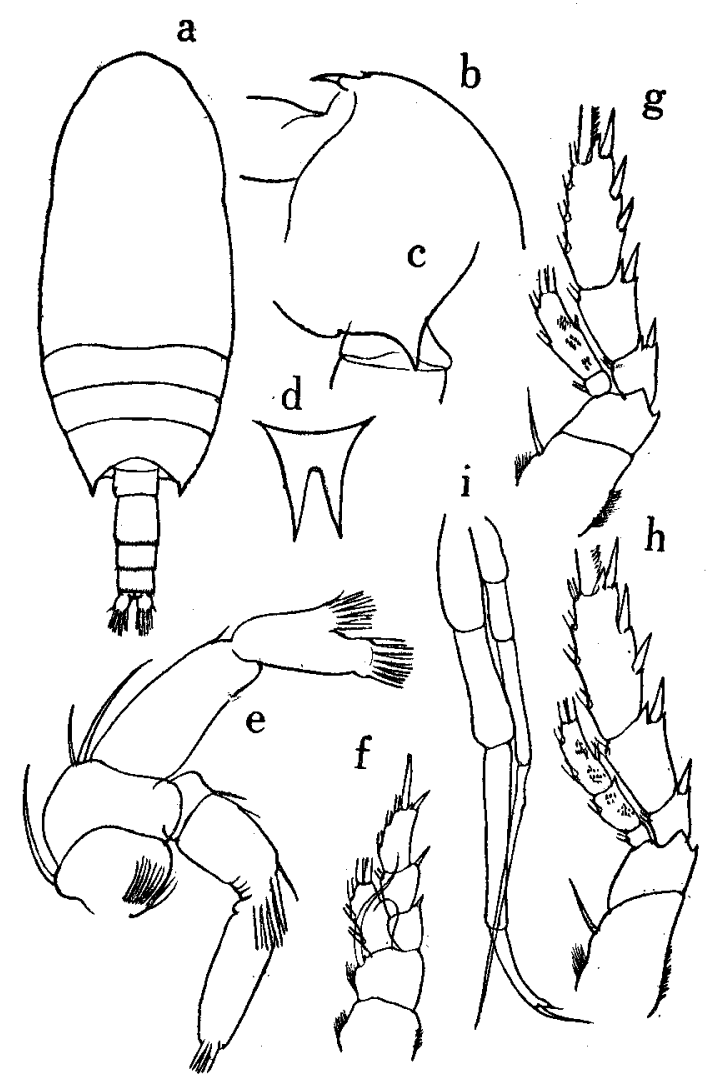

Fig. 29. Undinopsis angustus sp. nov.

$a$, Male : dorsal aspect; $b$ head, lateral aspect; $c$, last thoracic segment, lateral aspect; $d$, rostrum; $e$, 2nd antenna ; $f$, 1st leg; $g$, 2nd leg; $h, 4$ th leg; $i$, 5th pair of legs.

furnished with groups of minute spinules on posterior surface (fig. $h$ ); terminal spine of exopodite of third leg with 25 teeth, and that of fourth with 27 teeth.

Fifth pair of legs resemble those of male of the genus Chiridius (fig. $i$ ).

Remarks. The tropical specimen of Undinopsis, taken in the "Siboga", measured $1.7 \mathrm{~mm}$, the specimen from the Maldive, $1.2 \mathrm{~mm}$, and that from the Great Barrier Reef region, 1.5-1.63 (female) and 1.26-1.28 (male) $\mathrm{mm}$. The Maldive specimen for which 
WOLFENDEN proposed $U$. tropicus, differs from the northern species only in size and in the number of teeth on terminal spine of exopodite of second to fourth legs. MORI reported the occurrence of a female of $U$. bradyi from the neighbouring waters of Japan. His specimen is not identical with $U$. bradyi; the specimen has the thoracic spines not reaching the middle of genital segment; in first leg outer marginal spine of first joint of exopodite wanting; the specimen appears to be a member of Gaidius. The present specimen is close, in size, to the tropical specimen of Bradyidius armatus recorded by A. SCOTT, or to Unidinopsis tropicus recorded by WOLFENDEN and by FARRAN. If $U$. bradyi, the northern species, would have been distinct from $U$. tropicus, the tropical species, only in having coarse teeth on terminal spine of exopodite of second to fourth legs, the present specimen is not identical with $U$. bradyi, in having the male fifth legs differ from those of $U$. bradyi figured by SARs. FARRAN described the male of $U$. tropicus only on size without giving any figures. I propose to give to the present specimen a new name $U$. angustus.

Occurrence. One male from Sagami and two males from Suraga in the vertical hauls from the depth $1000 \mathrm{~m}$ to the surface, 1937.

\section{Genus Chiridius GIESBRECHT, 1892}

The following species have been recorded from various regions of the oceans: Chiridius gracilis FARRAN, Ch. poppei GIESBRECHT, Ch. obtusifrons SARS, Ch. modestus With, Ch. polaris Wolfenden, Ch. minor Wolfenden, Ch. antarcticus (Wolfenden) and $C h$. armatus (BOECK). The genus has, according to GIESBRECHT's original description, the following characters: general appearance as in Aetideus, but rostrum absent; endopodite of second antenna about half the length of exopodite; endopodite of mandible very short. According to his definition the following five species are comprised in Chiridius in its restricted sense: Ch. gracilis, Ch. poppei, Ch. obustifrons, Ch. modestus and $C h$. polaris. FARRAN included both rostrate and arostrate species in the same genus Chiridius from the reason that presence or absence of rostrum does not seem to be sufficient to separate generically the species which, in other respects, resemble closely each other. He added Chiridius armatus (BoECK), Faroella minor WOLFENDEN (=Aetideopsis minor (WOLFENDEN)) and Faroella antarcticus WolfEnden (=Aetideopsis antarcticus Wolfenden) into Chiridius. Here the genus Chiridius in wide sense comprises four genera, namely Chiridius GIEsBrecht, Undinopsis SARs, Aetideopsis Sars and Faroella Wolfenden. They resemble, indeed, each other in the structure of swimming legs, viz. first leg with 3-jointed exopodite and 1-jointed endopodite, and joints of exopodite have each an outer edge spine; second leg with 3-jointed exopodite and 2-jointed endopodite, though there are some exception in incomplete segmentation of joints of endopodite; third and fourth legs with 3-jointed exopodite and endopodite. Then, why does FARran not included 
Undinopsis SARS in his wide-sensed Chiridius? The genus Undinopsis differs from the members of Chiridius only in the armature on the posterior surface of joints of endopodite of second to fourth legs. GIESBRECHT defined as generic characters of Chiridius, beside the absence of rostrum, short endopodite of second antenna and mandible. In Aetideopsis and, perhaps, Faroella, endopodite of mandible is not small at all; in Chiridius SARs (Pseudoaetideus WoLFENDEN) endopodite of second antenna is about half the length of exopodite. These three genera, Aetideopsis, Faroella and Chiridius GIEsBrecht resemble each other in general appearance and in the structure of swimming legs with exception of the structure of second antenna and mandible. Absence or presence of rostrum is, by no means, insufficient reason of separating generically species. FARRAN himself distinguishes arostrate and rostrate species in his wide-sensed Chiridius. It seems reasonable, for the present, to follow GIESBrecht's definition of the genus Chiridius.

In the present collection five species have been detected of which two have been described, and the remaining three undescribed. Male specimens of this genus resemble so closely each other, differing only in size and in minute points of structure, that it is troublesome to connect them to the corresponding females.

\section{Chiridius gracilis FARRAN}

(Fig. 30, a-e)

Chiridius gracilis Farran, 1908, p. 30; A. SCOTt, 1909, p. 42; WOLFENDEN, 1911, p. ; With, 1915, p. 75; Farran, 1929, p. 229; FARRAN, 1936, p. 87; TANAKA, 1937, p. 225, fig. 6 .

Female. Length, $2.55 \mathrm{~mm}$. Posterior spines of last thoracic segment not divergent. In some specimens thoracic spines show a slight basal thickening, as figured by FARran (1929). Endopodite of second leg has a trace of segmentation between first and second joints on the anterior surface. Terminal spine of exopodite of fourth leg has 22 teeth. My previous specimen (1937) had 24, 28 and 26 teeth on the terminal spine of exopodite of second to fourth legs respectively. Fifth leg absent in female.

Male. Length, $2.32 \mathrm{~mm}$ : cephalothorax, $1.68 \mathrm{~mm}$; abdomen, $0.64 \mathrm{~mm}$. Cephalothorax oblong ovate, the greatest width $0.65 \mathrm{~mm}$ (fig. $a$ ). Lateral spines of last thoracic segment stout, with a wide base; last two thoracic segments completely fused (fig. c). Rostrum is represented by a thin triangular plate.

Abdomen 4-segmented, segments and furca with proportional lengths 18:26:25: $17: 2: 12=100$; furcal rami about 1.3 -times as long as wide. Second to fourth segments are fringed with fine teeth on the distal margin.

First antenna 23-jointed, extends to distal margin of last thoracic segment; joints are in the proportional lengths: 


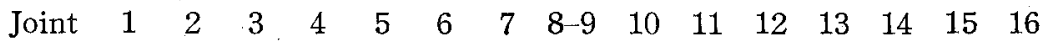

$$
\begin{aligned}
& \begin{array}{lllllllllllllll}
35 & 45 & 23 & 23 & 26 & 26 & 29 & 63 & 29 & 29 & 35 & 35 & 35 & 45 & 45
\end{array} \\
& \begin{array}{llllllll}
17 & 18 & 19 & 20 & 21 & 22 & 23 & 24-25
\end{array} \\
& \begin{array}{lllllllll}
52 & 52 & 59 & 63 & 46 & 60 & 60 & 75 & =1000 .
\end{array}
\end{aligned}
$$

Second antenna with exopodite about 1.4-times as long as endopodite; first basal joint with a row of hairs on the posterior surface. Mandible with short endopodite. First maxilla with 5 setae on outer lobe; 9 setae on exopodite; 9 setae on endopodite;

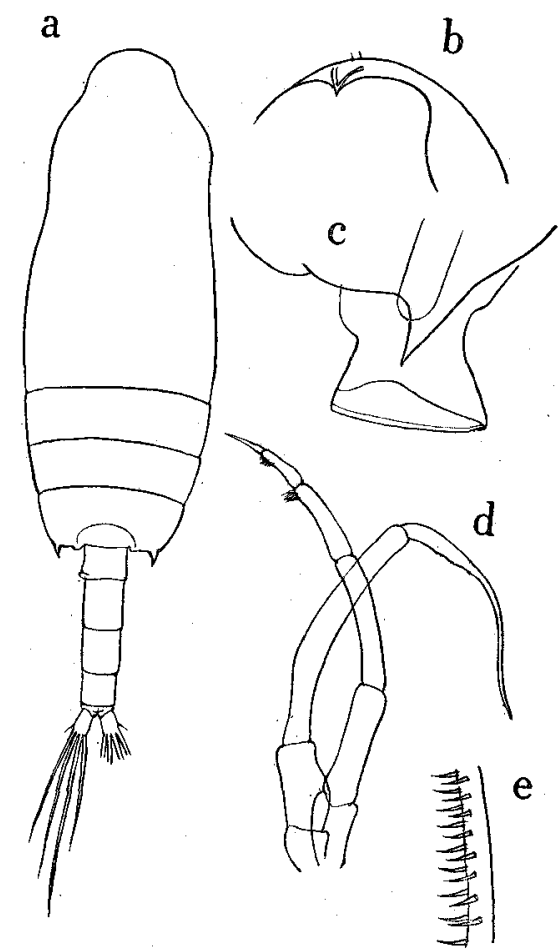

Fig. 30. Chiridius gracilis FARRAN.

$a$, Male : dorsal aspect; $b$, head, anterior aspect; $c$, last thoracic segment, lateral aspect; $d, 5$ th pair of legs.

first inner lobe with aesthetask-like filaments. Maxillipede slender; fifth joint of endopodite with a characteritic setae, as shown in the figure (fig. $e$ ).

First leg with 3-jointed exopodite. Second leg with 2-jointed endopodite; terminal spine of exopodite has 28 teeth. Third and fourth legs with 3 -jointed endopodite; terminal spines of exopodite of the same legs with 30 and 28 teeth respectively. Fifth pair of legs slender, resemble those of Ch. obtusifrons SAKS; right leg about as long as second swimming leg; left leg short, about four-fifths the length of right leg. 
Occurrence. Eight females from Suruga, July, 1937, 35 females and two males from Sagami, Nov. 1937, from deep waters.

Distribution. The species is widely distributed in the deep waters of the Pacific, Atlantic, Indian, Malay Archipelago.

\section{Chiridius poppei GIESBRECHT}

(Fig. 31, $a-f$ )

Chiridius poppei GIesbrecht, 1892, p. 224, t. 14, 36; A. SCOTt, 1909, p. 41; FarRaN, 1929, p. 229 ; JESPERSEN, 1934, p. 55; TANAKA, 1937, p. 254 ; BRODSKY, 1950, p. 152.

Female. Length, $1.83-1.87 \mathrm{~mm}$. Terminal spine of exopodite of second and third legs slightly longer than third joint of exopodite of the corresponding legs. Serration of terminal spines are straight and rather coarse. Fifth leg absent in female.

Male. Length, $1.52 \mathrm{~mm}$ : cephalothorax $1.11 \mathrm{~mm}$; abdomen, $0.41 \mathrm{~mm}$. Abdomen is contained 2.7-times in the length of cephalothorax. Cephalothorax robust; oral part of head much dilated in dorsal view. Head fused with first thoracic segment, and so are the fourth with the fifth (fig. a). Last thoracic segment produced into a small spine on each side; the spine is slender and convergent, bent posteriorly in the right angle to the ventral margin of last thoracic segment (fig. $d$ ). Rostrum short and one-pointed, rounded at the apex, directing downwards; in lateral view rostrum looks like beak; there is no trace of median crest (fig. $b$ ).

Abdomen 5-segmented, and furca with proportional lengths $20: 26: 20: 18: 2: 14$ $=100$. Anal segment very short, concealed beneath the foregoing. Furcal rami 1.4-times as long as wide; furcal seta longer than the combined lengths of abdominal segments and furca.

First antenna 23-jointed, reaches back to distal and of second abdominal segment; proportional lengths of the joints:

$\begin{array}{rrrrrrrccccccccc}\text { Joint } & 1 & 2 & 3 & 4 & 5 & 6 & 7 & 8-9-10 & 11 & 12 & 13 & 14 & 15 & 16 & 17 \\ & 38 & 26 & 19 & 19 & 23 & 23 & 23 & 72 & 30 & 30 & 34 & 37 & 45 & 49 & 57 \\ & 18 & 19 & 20 & 21 & 22 & 23 & 24 & 25 & & & & & & & \\ 60 & 72 & 76 & 53 & 64 & 68 & 64 & 19=1000 . & & & & & & \end{array}$

Second antenna with exopodite 1.4-times as long as endopodite; posterior surface of first basal joint bears rows of bristles. Mandible with a very strong seta on inner proximal margin of second basal joint. First maxilla with 7 setae on outer lobe, 9 setae on exopodite, 9 setae on endopodite. Second maxilla reduced. Maxillipede with second basal joint 1.25-times as long as the first basal; two proximal setae on anterior margin of second basal are fine and short.

First leg with a very short outer edge spine on first joint of exopodite (fig. $e$ ). In second leg articular membrane between first and second joints of endopodite is observed on the anterior surface; terminal spine of exopodite has 27 teeth. Third 
leg has 3-jointed endopodite; terminal spine of exopodite with 25 teeth. Fourth leg slender; terminal spine of exopodite has 20 teeth.

In fifth pair of legs terminal joint of right leg is long and slender; left leg as long as the combined lengths of terminal spine and three joints of exopodite of fourth leg taken together (fig. $f$ ).

Remarks. In the male specimen small lateral spines of last thoracic segment, long fifth legs and coarse teeth on terminal spine of exopodite of second to fourth legs distinguish the species from the foregoing.

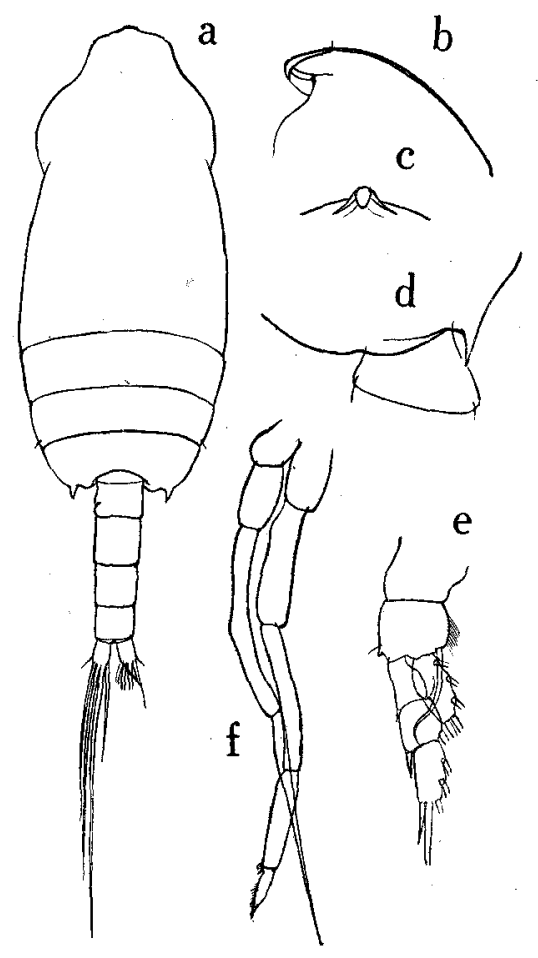

Fig. 31. Chiridius poppei GIESBRECHT.

$a$, Male: dorsal aspect; $b$, head, lateral aspect ; $c$, rostrum; anterior aspect; $d$, last thoracic segment, lateral aspect; $e, 1$ st leg; $f$, 5th pair of legs.

Occurrence. 16 females and one male from Sagami, and 20 females from Suruga, 1937; one male in a vertical haul from the depth 400-200 $\mathrm{m}$ in Suruga, Nov. 1938.

\section{Chiridius longispinus sp. nov.}

(Fig. 33, $a-h$ )

Male. Length, $1.52 \mathrm{~mm}$ : cephalothorax, $1.14 \mathrm{~mm}$; abdomen, $0.38 \mathrm{~mm}$. Abdomen 
is contained 3-times in the length of cephalothorax. Head fused with first thoracic segment. Line of fusion between fourth and fifth thoracic segments slightly visible from the dorsal (fig. a). Last thoracic segment is produced into acute spines, extending beyond the end of first abdominal segment; the spines are longer and wider in proportion than in the male of $\mathrm{Ch}$. poppei (fig. $d$ ). Rostrum one-pointed, beak-like in lateral view; base of rostrum well-marked in anterior aspect (fig. $b, c$ ).

Abdomen 5-segmented, segments and furca with proportional lengths $16: 26: 21$ : $19: 2: 16=100$. Furcal rami about 1.4-times as long as wide. Distal margin of second to fourth segments are fringed with fine teeth.

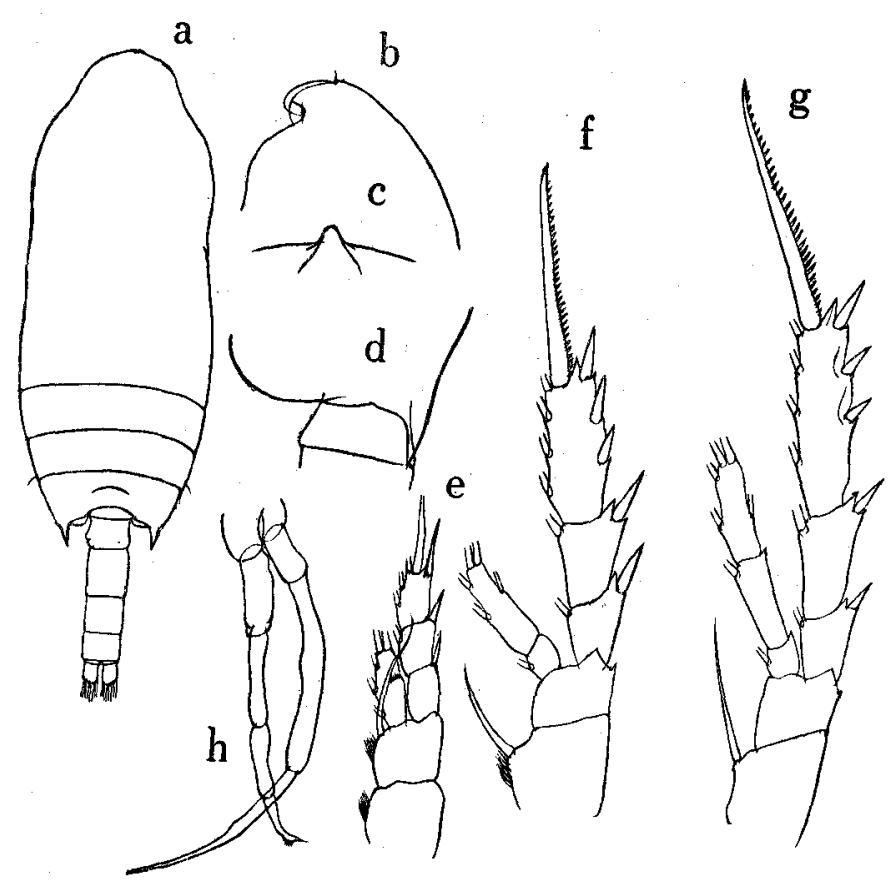

Fig. 32. Chiridius longispinus sp. nov.

$a$, Male : dorsal aspect ; $b$, head, lateral aspect; $c$, rostrum, anterodorsal aspect ; $d$, last thoracic segment, lateral aspect; $e$, 1st leg; $f$, 2nd leg; $g$, 4th leg; $h$, 5th pair of legs.

Terminal joints of first antenna broken off; the remaining 18 joints with proportional lengths:

\begin{tabular}{|c|c|c|c|c|c|c|c|c|c|c|c|c|c|c|c|}
\hline \multirow{2}{*}{ Joint } & 1 & 2 & 3 & 4 & 5 & 6 & 7 & $8-9-10$ & 11 & 12 & 13 & 14 & 15 & 16 & 17 \\
\hline & 9 & 13 & 8 & 7 & 7 & 7 & 8 & 25 & 8 & 10 & 11. & 10 & 12 & 13 & 14 \\
\hline & 18 & 19 & 20 & & & & & & & & & & & & \\
\hline & 14 & 17 & & & & & & & & & & & & & \\
\hline
\end{tabular}


joints 20 ard 21 are fused on the right. In another specimen first antenna extends to the end of genital segment. Second antenna with exopodite 1.3-times as long as endopodite. Mandible with a short endopodite, bearing 9 setae on the distal margin. In first maxilla the spinulation of various parts as follows: outer lobe has 6 setae; exopodite has 9 setae; endopodite has 9 setae; second basal has 2 setae; third inner lobe has one seta; second inner lobe has one seta respectively. Second maxilla much reduced.

First leg has an outer edge spine on first joint of exopodite reaching about distal margin of second joint of exopodite (fig. e). Second leg with 2-jointed endopodite; terminal spine of exopodite long, and has 35 teeth (fig. $f$ ). Exopodite of third leg missing. Fourth leg has 3 -jointed exopodite and endopodite; terminal spine of exopodite has 33 teeth (fig. $g$ ). Fifth pair of legs are short; they are shorter than half the length of fourth leg (fig. $h$ ).

Remarks. The present specimen resembles male of Ch. poppei in its small size, but slender cephalothorax, shape of thoracic spines, long terminal spines of exopodite of second to fourth legs and the proportional lengths of fifth pair of legs are different from those of the former.

Occurrence. Each an adult male both from Sagami and Suraga from the depth $1000 \mathrm{~m}$ to the surface, Nov, and Dec. 1937.

\section{Chiridius molestus sp. nov.}

(Fig. 33, $a-f$ )

Male. Length, $2.04 \mathrm{~mm}$ : cephalothorax, $1.43 \mathrm{~mm}$; abdomen, $0.61 \mathrm{~mm}$. Body elongate ovate; the greatest width slightly less than half the length of cephalothorax. Head conspicuously dilated in oral region. Fourth and fifth thoracic segments fused (fig. a). Posterior margin of last thoracic segment with minute spines which are more convergent than those found in the male of $\mathrm{Ch}$. poppei (fig. c). Rostrum as those of females of other members of the genus (fig. $b$ ).

Abdominal segments and furca with proportional lengths $17: 25: 23: 19: 3: 13$ $=100$; furcal rami 1.5-times as long as wide.

First antenna 23-jointed, reaches back to the middle of third abdominal segment; proportional lengths of joints as follows:

$$
\begin{array}{rrrrrrrccccccccc}
\text { Joint } & 1 & 2 & 3 & 4 & 5 & 6 & 7 & 8-9-10 & 11 & 12 & 13 & 14 & 15 & 16 & 17 \\
& 28 & 22 & 17 & 17 & 17 & 21 & 21 & 68 & 28 & 34 & 34 & 34 & 45 & 56 & 62 \\
18 & 19 & 20 & 21 & 22 & 23 & 24 & 25 & & & & & & & \\
62 & 79 & 79 & 56 & 73 & 68 & 62 & 17=1000 & & & & & & &
\end{array}
$$

joints 20 and 21 are fused on the right side; joint 24 is incompletely separate from the 25th; proximal joints are furnished with well developed aesthetasks. Second antenna with exopodite about 1.5-times as long as endopodite. Endopodite of mandible 
is short, and has 8 setae. Second maxilla reduced much. Second basal joint of maxillipede is longer than the first; first joint of endopodite has $4^{*}$ setae, of which the middle one is very strong.

In first leg first joint of exopodite has an outer edge spine, not reaching the end of second joint of exopodite (fig. $d$ ). Second leg with 1 -jointed endopodite; line

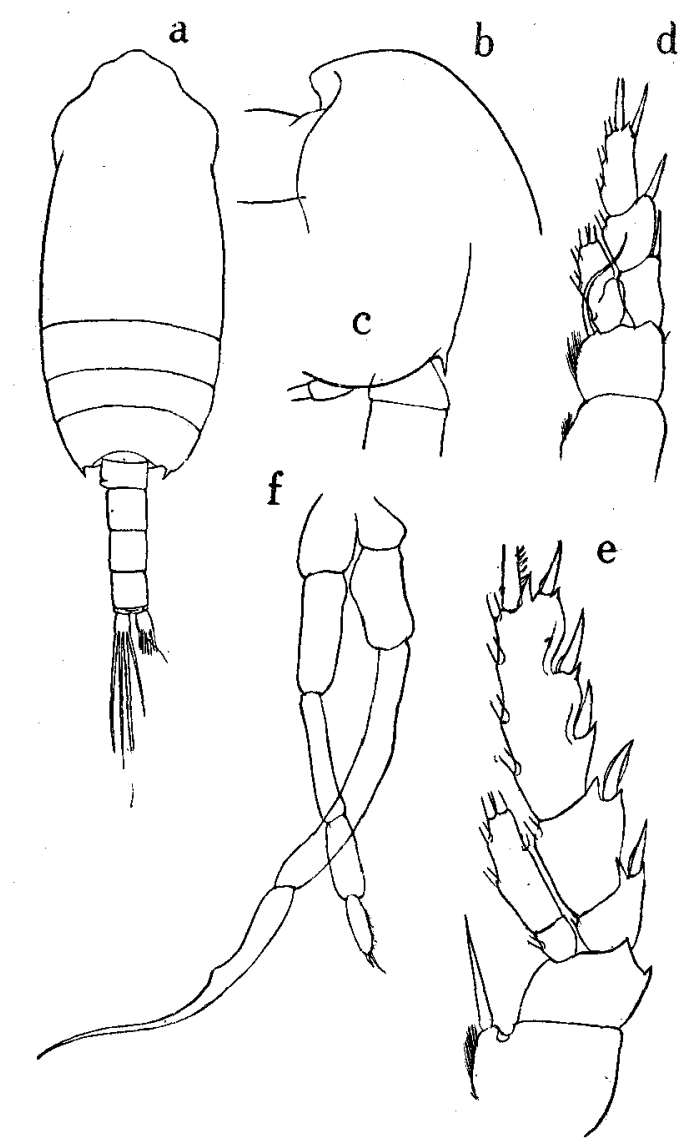

Fig. 33. Chiridius molestus sp. nov.

$a$, Male : dorsal aspect; $b$, head, lateral aspect; $c$, last thoracic segment, lateral aspect; $d$, 1st leg; $e$, 2nd leg; $f, 5$ th pair of legs.

of fusion between first and second joints is found on the anterior surface; terminal spine of exopodite has 32 teeth (fig. $e$ ). Third leg with 3-jointed endopodite; terminal spine of exopodite has 29 teeth. Fourth leg slender; terminal spine of exopodite has 24 teeth. Fifth pair of legs slender, resemble those of Ch. obtusifrons SARS; left leg about two-thirds the length of the right; terminal joint of left leg has two unequal spines on the apex (fig. $f$ ). 
Remarks. The specimens resemble $C h$. gracilis, but lateral spines of last thoracic segment are small.

Occurrence. Two males from Suruga, July, 1937, and three males from Sagami, Nov. 1937, in the vertical hauls from the depth $1000 \mathrm{~m}$ to the surface. The specimen is the richest in number among the male of the genus.

\section{Chiridius carnosus sp. nov.}

(Fig. 34, $a-f$ )

Male. Length, $2.36 \mathrm{~mm}$ : cephalothorax, $1.77 \mathrm{~mm}$; abdomen, $0.51 \mathrm{~mm}$. General appearance as those of males of Aetideus. Cephalothorax elongate ovate. Head fused

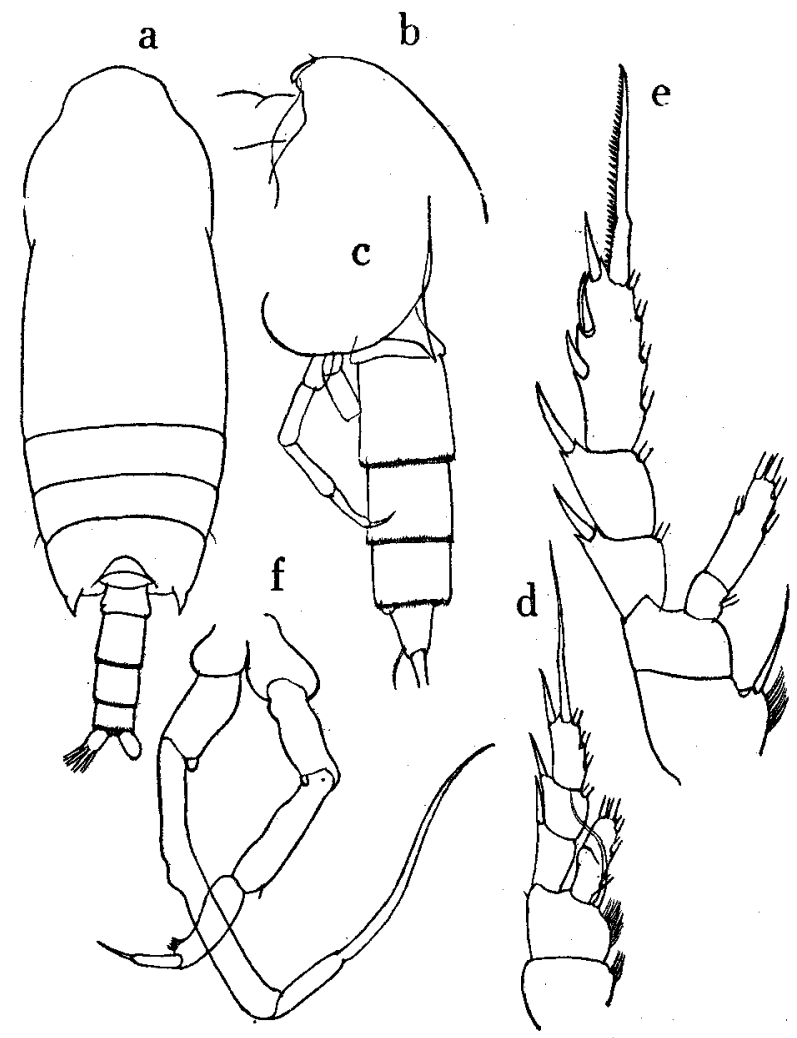

Fig. 34. Chiridius carnosus sp. nov.

$a$, Male : dorsal aspect; $b$, head, lateral aspect; $c$, last thoracic segment and abdomen, lateral aspect; $d$, 1st leg; $e$, 2nd leg; $f, 5$ th pair of legs.

with first thoracic segment; fourth and fifth thoracic segments are incompletely fused (fig. a). Base of lateral spines of last thoracic segment wide (fig. $c$ ). Rostrum one- 
pointed, looks like a beak (fig. $b$ ).

Abdomen 5-segmented, segments and furca with proportional length 18:22:25: $18: 2: 15=100$. Anal segment very short, concealed beneath the foregoing. Furcal rami about 1.3-times as long as wide.

First antenna 23-jointed, reaches back to distal end of second abdominal segment; joints are in proportional lengths.

$\begin{array}{rrrrrrrccccccccc}\text { Joint } & 1 & 2 & 3 & 4 & 5 & 6 & 7 & 8-9-10 & 11 & 12 & 13 & 14 & 15 & 16 & 17 \\ & 71 & 47 & 24 & 19 & 24 & 28 & 28 & 96 & 28 & 28 & 33 & 33 & 43 & 47 & 52 \\ 18 & 19 & 20 & 21 & 22 & 23 & 24 & 25 & & & & & & & \\ 52 & 62 & 62 & 43 & 62 & 57 & 47 & 14=1000 ; & & & & & & \end{array}$

joints 20 and 21 are fused on the right proximal joints with long aesthetasks. Second antenna with exopodite 1.25-times as long as endopodite; first basal joint has a row of long stiff hairs. Mandible has a short endopodite. First maxilla has 9 setae on endopodite, 5 setae first outer lobe, 9 setae on exopodite. Second maxilla shows no characteristic features. In maxillipede first and second basal joints, and endopodite have the proportional lengths: 35,24 and 18.

First leg with 3 -jointed exopodite; outer edge spines of the exopodite slender and long (fig. $d$ ). Second leg with 2 -jointed endopodite; terminal spine of exopodite has 37 teeth (fig. $e$ ). Third leg has 3-jointed endopodite; exopodite broken off. Fourth leg broken off; first basal joint without inner marginal hairs. Ffth pair of legs resemble those of Ch. armatus SARS, with a very rudimentary endopodite on second basal joint on each side; distal joint of the right leg very slender and long (fig. $f$ ).

Remarks. The specimen appears to be a member of the genus Chiridius, but the structure of the fifth pair of the male legs indicates a close relationship to Aetideopsis.

Occurrence One male from Sagami, Nov. 1937, in the vertical haul from 1000 $-0 \mathrm{~m}$.

\section{Genus Chiridiella G. O. SARS, 1907}

Two species belonging to the genus have been detected in the collection. The genus differs from Chiridius in the followings: last thoracic segment has no lateral spines; exopodite of second antenna little longer than endopodite; exopodite of mandible small; first maxilla reduced; second maxilla and maxillipede very characteristic; first leg has 1-jointed endopodite; third and fourth legs with 3-jointed exopodite and endopodite, the joints of both exopodite and endopodite broad. Fifth leg absent in female. These characteristics indicate that the genus is quite a stranger among the family Aetideidae, although male fifth pair of legs show close relationship to Gaidius and Gaetanus. The systematic position remains uncetain till more species that have the similar structure in mandible and maxillae to those of this genus have been found. 


\section{Chiridiella macrodactyla $\mathrm{G}$. O. SARS}

(Fig. 35, $a-g$ )

Chiridiella macrodactyla FARRAN, 1908, p. 46, pl. 4 ; A. SCOTT, 1909, p. 79, pl. 35; G. O. SARS, 1925 , p. 50 , pl. 16.

Female. Length, $2.57 \mathrm{~mm}$ : cephalothorax, $2.13 \mathrm{~mm}$; abdomen, $0.44 \mathrm{~mm}$. Cephalothorax ovate in outline. Head fused with first thoracic segment (fig. a). Last two thoracic segments fused. Rostrum absent.

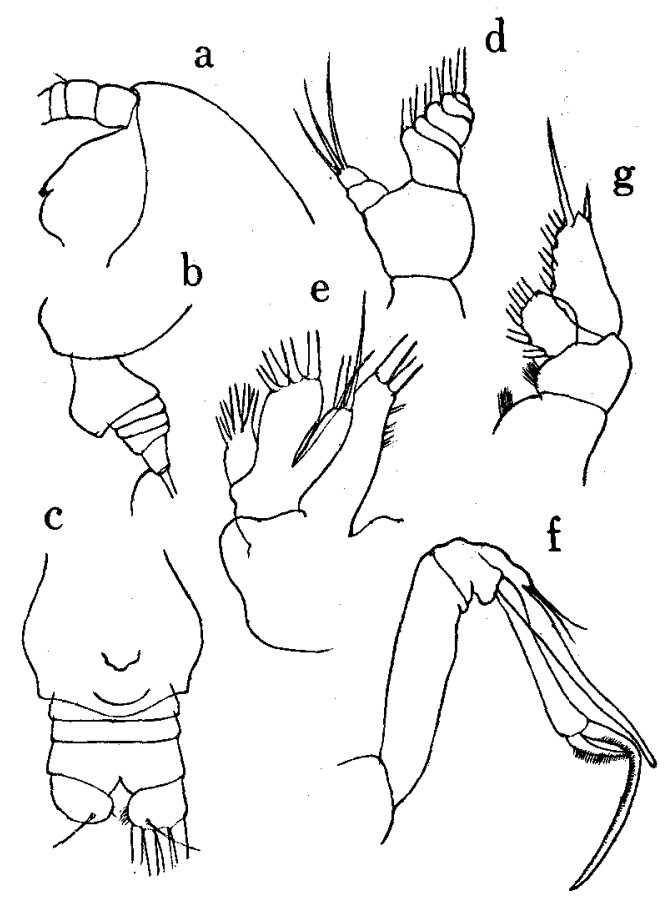

Fig. 35. Chiridiella macrodactyla G. O. SARS.

$a$, Female: head, lateral aspect; $b$, last thoracic segment and abdomen, lateral aspect; $c$. abdomen, ventral aspect; $d$, mandible palp; $v$, 1st maxilla; $f$, 2nd maxilla; $g$, 1st leg.

Abdomen 4-segmented, segment and furca with proportional lengths $40: 12: 12$ : $12: 20: 16=100$. Genital segment much wider than long, and produced considerably below. Furcal rami wider than long, carries short setae (fig. $b, c$ ).

Second antenna has 7 -jointed exopodite which is 1.2 -times as long as endopodite (31:26). Mandible simple; endopodite bears three setae on the distal joint; exopodite has five setae (fig. $d$ ); biting part strong and well developed. In first maxillar exopodite with five setae, endopodite with four setae, third inner lobe with three setae, first inner 
lobe ten setae; setae on outer lobe were not observed (fig. e). Second maxilla very characteristic; according to SARS, it is furnished with four lobes, among which the proximal two are simple, and each carries two setae; in the present specimen first lobe was absent; second lobe is small and has no seta; distal two lobes as those described by SARS (fig. $f$ ). Maxillipede slender and long; the second basal about 1.4-times as long as the first.

First leg has 1-jointed exopodite and endopodite (fig. g). Second leg has $3-$ jointed exopodite and 1-jointed endopodite. Third and fourth legs have 3 -jointed exopodite and endopodite. Fifth leg absent.

Remarks. The present specimen, except minute points of difference in the structure of mandible, maxillae, agrees fairly well with the SARS' description and figures.

Occurrence. One adult female from Suruga in a haul from 1000-0 m, July, 1937.

Distribution. The species has been recorded from the deep waters of the Atlantic and Malay Archipelago.

\section{Chiridiella brachydactyla G. O. SARS}

(Fig. 36, $a-j$ )

Chiridiella brachydactyla SARS, 1925, p. 51. (Female)

Male. Length, $2.36 \mathrm{~mm}$ : cephalothorax, $1.75 \mathrm{~mm}$; abdomen, $0.61 \mathrm{~mm}$. Cephalothorax oblong ovate. Head fused with first thoracic segment. Fourth and fifth thoracic segments fused (fig. $a, b$ ). Lateral corners of last thoracic segment rounded (fig. c).

Abdomen 5-segmented, segments and furca in the proportional lengths $27: 21$ : $15: 18: 6: 15=100$; furcal rami about as long as wide (fig. $d$ ).

First antenna 24-jointed, exceeds distal margin of furca by terminal two joints; joints are in the proportional length:

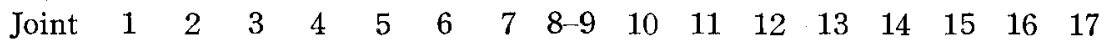

$$
\begin{aligned}
& \begin{array}{llllllllllllllll}
21 & 24 & 18 & 21 & 21 & 24 & 24 & 45 & 29 & 32 & 34 & 47 & 47 & 58 & 66 & 66
\end{array} \\
& \begin{array}{llllllll}
18 & 19 & 20 & 21 & 22 & 23 & 24 & 25
\end{array} \\
& \begin{array}{llllllll}
61 & 71 & 71 & 61 & 58 & 50 & 42 & 11=1000 \text {; }
\end{array}
\end{aligned}
$$

joints 12 and 13 are incompletely fused. Second antenna has exopodite about 1.3times as long as endopodite; first basal joint has a tuft of hairs on the posterior surface; first joint of endopodite very voluminous (fig. $e$ ). Mandible has exopodite about as long as endopodite; biting part thin-skined (fig. $f$ ). In first maxilla outer lobe has 5 long setae, exopodite has 10 setae, endopodite and inner lobes reduced. Second maxilla reduced; fourth and fifth lobes are large, each with a strong spine at the apex (fig. $g$ ). Maxillipede slender; fifth lobe of first basal joint has a peculiar spine folked at the apex (fig. $h$ ).

First leg has 1-jointed exopodite and endopodite. Second leg with 3-jointed 
exopodite and 2-jointed endopodite; according to SArs, endopodite is 1 -jointed in the female, but in the present male specimen line of separation between first and second joints well marked on either side of the joint, especially vivid on anterior surface; joints of exopodite broad; the terminal spine of the exopodite has 45 teeth (fig. $i$ ). Third and fourth legs with 3-jointed exopodite and endopodite. Fifth pair of legs resemble those of Gaidius (fig. $f$ ).

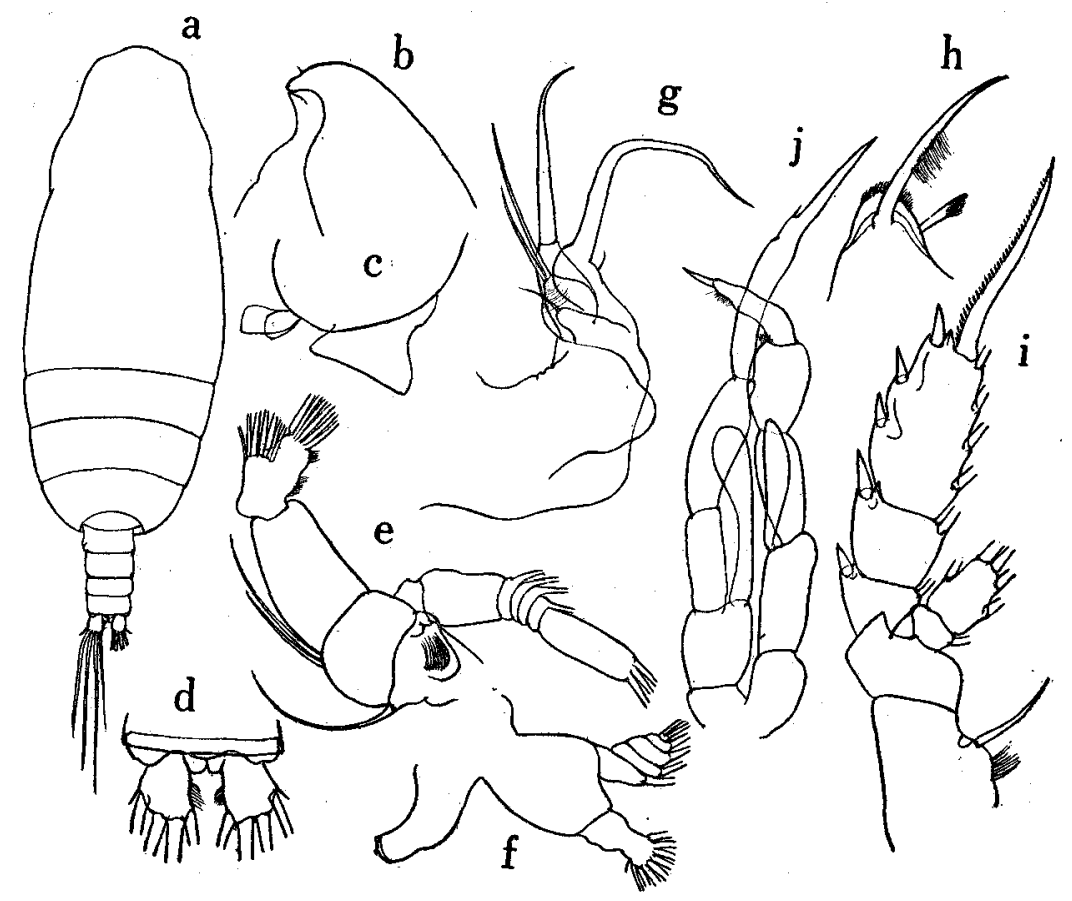

Fig. 36. Chiridiella brachydactyla G. O. SARS.

$a$, Male: dorsal aspect ; $b$, head, lateral aspect ; $c$, last thoracic segment, lateral aspect ; $d$, anal segment and furca ; dorsal aspect ; $e$, 2nd antenna ; $f$, mandible ; $g$, 2nd maxilla; $h$, distal margin of 1 st basal joint of maxillipede; $i$, 2nd leg; $j, 5$ th pair of legs.

Remarks. The male specimen has not been reported before. Some authors comprises the genus Chiridiella in the family Euchaetidae, but SARS rightly comprised it in the family Aetideidae. The structure of male fifth pair of legs indicates that the genus is closely allied to the member of the family Aetideidae.

Occurrence. One adult male from Sagami, in a vertical haul from $1000 \mathrm{~m}$ to the surface, Nov. 1937.

Distribution. The species has been recorded from the deep waters of the Atlantic. 


\section{Genus Gaidius GIESBRECHT, 1895}

Up to the present time, none of the species belonging to the genus has been recorded from Japanese waters. I have found in the collection the following species: Gaidius tenuispinus SARS, G. minutus SARS, G. brevispinus SARs and G, moderatus n.sp. The genus is characterized by one-pointed rostrum, short endopodite of second antenna, and two jointed endopodite of first leg. Male resembles female in general appearance, and is characterized by the reduction of thoracic spine; mouth parts and outer edge spine of second joint of exopodite of first leg are also reduced. Fifth pair of legs have each a rudimentary endopodite on second basal joint.

\section{Gaidius tenuispinus G. O. SARS, 1900}

(Fig. 37, $a-k$ )

Chiridius tenuispinus SARS, 1903, p. 30; Gaidius similis A. ScOTT, 1909, p. 51, pl. 7; Gaidius tenuispinus ESTERLY, 1911, p. 316; WiTh, 1915, p. 89; SARS, 1925, p. 46; FARRAN, 1926, p. 249; Farran, 1929, p. 231 ; Sewell, 1929, p. 100 ; JeSpersen, 1934, p. 58 ; Brodsky, 1950 , p. 164 ; VerVOORT, 1950, p. 15 ; VerVOORT, 1951, p. 81.

Female. Length, $3.44 \mathrm{~mm}$ : cephalothorax, $2.75 \mathrm{~mm}$; abdomen, $0.69 \mathrm{~mm}$. The specimen agrees quite well with the description and figures given by SARS. Lateral spines of last thoracic segment slender and long (fig. $a, b, c$ ).

Abdomen 4-segmented, segments and furca in the proportional lengths $41: 18$ : $13: 10: 18=100$; furcal rami about $1.3-$ times as long as wide.

First antenna 24-jointed, extends about to distal margin of 2nd abdominal segment; joints with proportional lengths:

$\begin{array}{rrrrrrrrlllllllll}\text { Joint } & 1 & 2 & 3 & 4 & 5 & 6 & 7 & 8-9 & 10 & 11 & 12 & 13 & 14 & 15 & 16 & 17 \\ & 29 & 50 & 23 & 26 & 26 & 29 & 29 & 44 & 23 & 23 & 23 & 41 & 41 & 44 & 48 & 50 \\ 18 & 19 & 20 & 21 & 22 & 23 & 24 & 25 & & & & & & & & \\ 53 & 70 & 54 & 53 & 70 & 67 & 56 & 20=1000 . & & & & & & \end{array}$

Mouth parts and swimming legs as figured by SARS. Number of teeth on terminal spine of exopodite of second to fourth legs are 23,20 and 26 respectively. First basal joint of maxillipede (fig. $d$ ) and first leg (fig. $e$ ) as shown in the figure.

Male. Length, $2.07 \mathrm{~mm}$ : cephalothorax, $1.67 \mathrm{~mm}$; abdomen, $0.60 \mathrm{~mm}$. The general appearance as SARS' figure (fig. $f, g, i$ ). Rostrum somewhat differs from the figures given by WITH; it is not so sharply produced (fig. $h$ ). Abdomen 5-segmented, segments and furca with proportional lengths $19: 30: 19: 19: 2: 11=100$; furcal rami about as long as wide.

First antenna 21-jointed, extends to distal margin of second abdominal segment; joints are in proportional. length: 


$\begin{array}{rrrrrrrrccccccc}\text { Joint } & 1 & 2 & 3 & 4 & 5 & 6 & 7 & 8-9-10 & 11 & 12-13 & 14 & 15 & 16 & 17 \\ & 27 & 27 & 16 & 21 & 26 & 26 & 32 & 69 & 27 & 63 & 37 & 48 & 53 & 58 \\ 18 & 19 & 20-21 & 22 & 23 & 24 & 25 & & & & & & \\ 63 & 74 & 128 & 79 & 74 & 43 & \mathbf{1 1}=1000 . & & & & & \end{array}$

Second antenna with exopodite about as long as endopodite; first basal joint has rows of hairs on posterior surface; and a strong inner marginal seta. Mandible with a

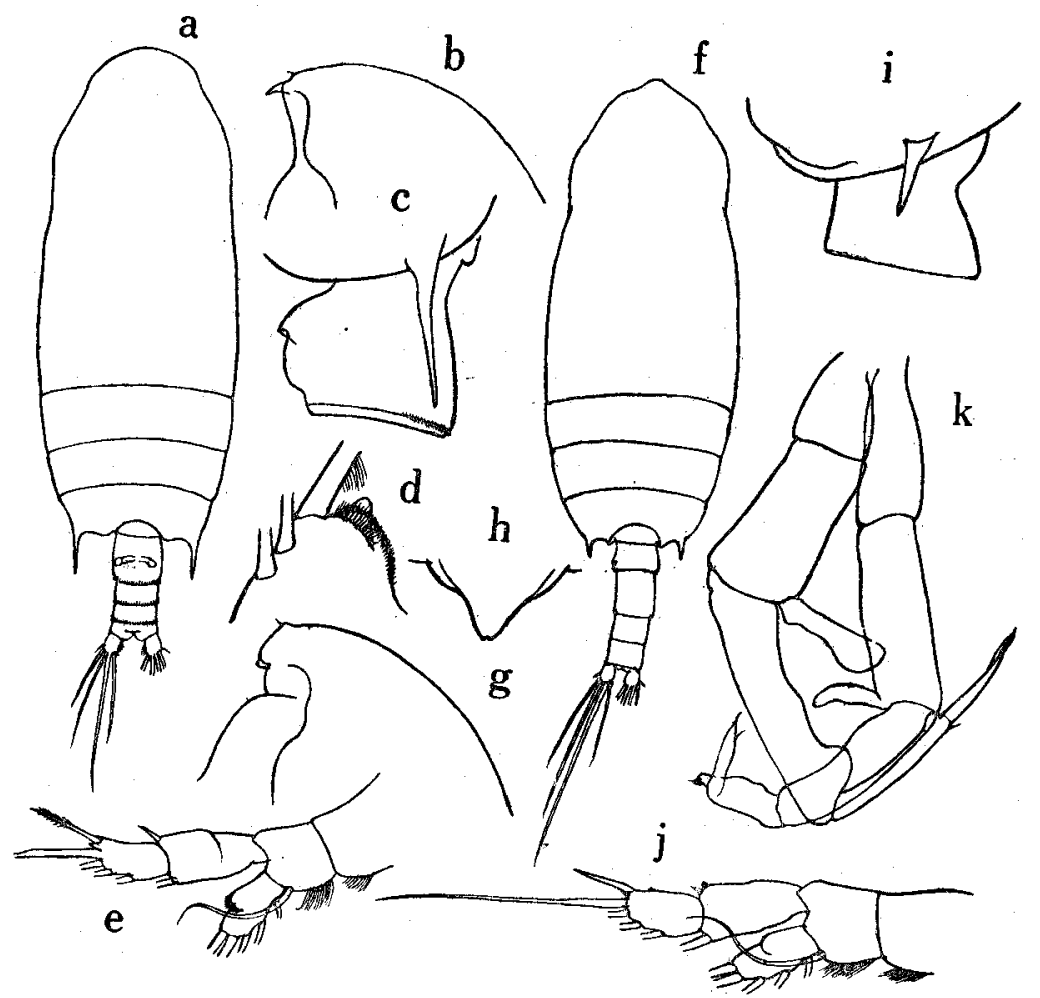

Fig. 37. Gaidius tenuispinus (G. O. SARS).

$a$, Female: dorsal aspect; $b$, head, lateral aspect; $c$, last thoracic segment and genital segment, lateral aspect; $d$, distal margin of 1st basal joint of maxillipede ; $e$, 1st leg; $f$, Male: dorsal aspect; $g$, head, lateral aspect; $h$, rostrum, anterior aspect; $i$, last thoracic segment, lateral aspect; $j$, 1st leg; $k$, 5th pair of legs.

robust second basal joint. Outer lobe of maxilla has 7 setae, exopodite has 11 setae, endopodite has 9 setae. Second maxilla reduced and thin-skined. Maxillipede has slender basal joints.

In first leg first and second joints of exopodite are fused; outer edge spine of second joint of exopodite is very minute; third joint of exopodite has a slight prominence furnished with fine spinules on the distal one-third of the outer margin 
(fig. $j$ ). Second leg has 1 -jointed endopodite; in exopodite outer edge spine of second joint reaches the base of proximal spine of third joint; distal outer edge spine of third joint is about half as long as third joint of exopodite; terminal spine has 24 teeth. Third and fourth legs have each 3-jointed endopodite; number of teeth on terminal spine of exopodite are 17, and 14 respectively. Fifth pair of legs as figured by SARS (fig. $k$ ).

Remarks. Male specimen resembles Gaidius similis A. Scott, but differs from it in the followings: shape of rostrum, minute outer edge spine of second joint of exopodite of first leg, one-jointed endopodite of second leg, and small size.

Occurrence. Two adult and three immature females and one adult male from Sagami, in vertical hauls from $1000-0 \mathrm{~m}$.

Distribution. The species appears to be widely distributed in the Pacific, Atlantic and Indian Oceans.

\section{Gaidius brevispinus G. O. SARS}

(Fig. 38, $a-k$ )

Gaidius brevispinus SARS, 1903, p. 162; With, 1915, p. 94 ; SARS, 1925, p. 48; BrodSky, 1950, p. 158.

Female. Length, $4.40 \mathrm{~mm}$ : cephalothorax, $3.45 \mathrm{~mm}$; abdomen, $0.95 \mathrm{~mm}$; so abdomen is contained 3.6-times in length of cephalothorax. Cephalothorax moderately robust (fig. $a, b$ ). Lateral corners of last thoracic segment broadly rounded, with short oblique spine (fig. $c$ ). Rostrum one-pointed, slightly notched at the apex.

Abdomen 4-segmented, segments and furca with proportional length 40:15: $9: 17: 19=100$. Genital segment robust. Furcal rami 1.4-times as long as wide.

First antenna 24-jointed, reaches back to distal end of third abdominal segment. Mouth parts as those of other member of the genus; second maxilla has a lamellous process on the posterior margin about the middle of first basal joint. Maxillipede as shown in the figure (fig. $d$ ).

First leg has 3-jointed exopodite and 1-jointed endopodite; outer edge spine of second joint of exopodite is long and slender. Second leg has 3-jointed exopodite and 2-jointed endopodite; terminal spine of exopodite has 21 teeth (fig. $e$ ). Terminal spine of exopodite of third and fourth legs have each 21 and 27 teeth respectively. In fourth leg first basal joint has a row of bristles on the base of the inner marginal seta. Proportional lengths of terminal spine of exopodite to third joint of exopodite are as follows: second leg, $26: 21$, third leg, $28: 25$, fourth leg, $28: 26$.

Male. Length $2.94 \mathrm{~mm}$ : cephalothorax, $2.26 \mathrm{~mm}$; abdomen, $0.68 \mathrm{~mm}$. Cephalothorax robust; the greatest width $1.02 \mathrm{~mm}$; lateral spines of last thoracic segment small (fig. g). Frontal organ prominent (fig. $f$ ). Rostrum notched at the apex (fig. $h$ ).

Abdomen 5-segmented, segments and furca with proportional lengths $23: 26: 18$ : $15: 3: 15=100$. Furcal rami 1.2 -times as long as wide. Second to fourth segments 
are fringed with fine teeth on the distal margin.

First antenna 21-jointed, extends to distal margin of second abdominal segment; joints are in the proportional lengths:
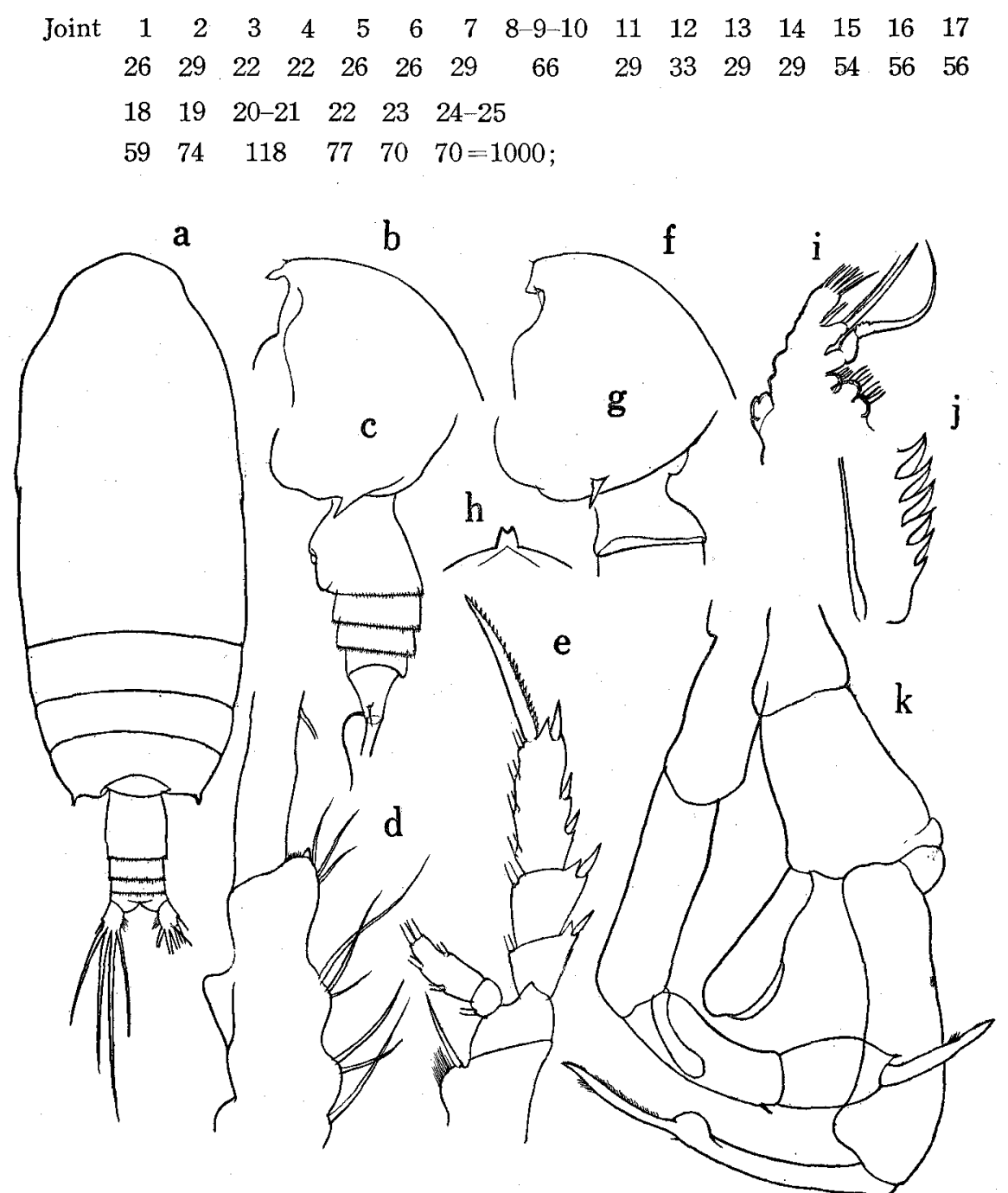

Fig. 38. Gaidius brevispinus G. O. SARS.

$a$, Female: dorsal aspect ; $b$, head, lateral aspect; $c$, last thoracic segment and abdomen, lateral aspect; $d, 1$ st basal joint of maxillipede; $e$, 2nd leg; $f$, Male: head, lateral aspect; $g$, last thoracic segment, lateral aspect ; $h$, rostrum, anterior aspect; $i$, 2nd maxilla; $j$, terminal spine of exopodite of 4 th leg; $k$, 5th pair of legs.

joints 24-25 are longer in proportion than those of G. tenuispinus. Second antenna, and mandible as in $G$. tenuispinus. First maxilla with $7+2$ setae on outer lobe. Second maxilla reduced; fourth lobe has a remarkable seta (fig. $i$ ). Maxillipede slender. 
First leg with 3-jointed exopodite second joint of exopodite with a minute outer edge spine; no protuberance on outer margin of third joint. Second leg with 2jointed endopodite; terminal spine of exopodite has 27 teeth which is connected with lamellous thin plate. Third and fourth legs with 3-jointed endopodite; number of teeth on terminal spine of exopodite are 23 and 29 respectively (fig. $j$ ); first basal joint of fourth leg is smooth on the inner margin. Fifth pair of legs as those of the preceding species, and agree fairly well with SARS' figures of tenuispinus except that the endopodite of the left leg is shorter; second joint of exopodite of left leg is robust, and carries a single small spine on the inner distal margin (fig. $k$ ).

Remarks. The female specimens of Gaidius brevispinus $(4.8 \mathrm{~mm})$, G. intermedius WOLFENDEN (=Mesogaidius intermedius) $(4.0-4.15 \mathrm{~mm}$ ) and G. affinis SARS (3.60 mm) resemble each other in having a short spine on lateral corner of last thoracic segment; these three species have also a lamellous process on first basal joint of the maxillipede; their first antennae are of about equal proportional lengths. Comparing the present specimen with these three species, lamellous process of maxillipede comes nearest to that of G. brevispinus; outer edge spine of second joint of exopodite of first leg is longer than that of $G$. intermedius. It seems to be most reasonable to regard the present specimen as G. brevispinus.

Occurrence. Four adult females and one male from Sagami, in vertical hauls 1000-0 m.

Distribution. The species has been recorded from the Atlantic.

\section{Gaidius minutus G. O. SARS}

(Fig. 39, $a-f$ )

Gaidius minutus SARS, 1925, p. 49 ; SEWELL, 1929, p. 100.

Female. Length, $2.62 \mathrm{~mm}$ : cephalothorax, $2.12 \mathrm{~mm}$; abdomen, $0.50 \mathrm{~mm}$. Cephalothorax robust. Head fused with first thoracic segment; the fourth and fifth are fused (fig. $a, b, c$ ). Last thoracic segment produced into a small nodule on each side. Rostrum short, one-pointed, slightly notched at the apex (fig $d$ ).

Abdomen 4-segmented, segments and furca with proportional lengths 42:13:11: $11: 23=100$. Genital segment produced below. First three segments are fringed with fine teeth on the distal margin. Furcal rami 1.5-times as long as wide.

First antenna 24-jointed, reaches back to distal end of abdomen; joints are in the following proportional lengths:

$$
\begin{array}{rrrrrrrrrrrrrrrrr}
\text { Joint } & 1 & 2 & 3 & 4 & 5 & 6 & 7 & 8-9 & 10 & 11 & 12 & 13 & 14 & 15 & 16 & 17 \\
& 34 & 37 & 24 & 24 & 27 & 30 & 30 & 44 & 24 & 27 & 27 & 44 & 44 & 47 & 50 & 50 \\
18 & 19 & 20 & 21 & 22 & 23 & 24 & 25 & & & & & & & & \\
54 & 67 & 61 & 50 & 67 & 61 & 54 & 24=1000 . & & & & & &
\end{array}
$$


Second antenna with exopodite a little longer than endopodite. First maxilla with 9 setae on outer lobe, 11 setae on exopodite, 14 setae on endopodite, 5 setae on second basal joint, 4 setae on third inner lobe, 14 setae on first inner lobe. In maxillipede distal inner lobe of first basal joint has, beside usual 3 setae, a small lamellous process.

In first leg first and second joints of exopodite fused; outer edge spine of third joint is longer than the joint itself (fig. e). Second to fourth legs are of Aetideus-

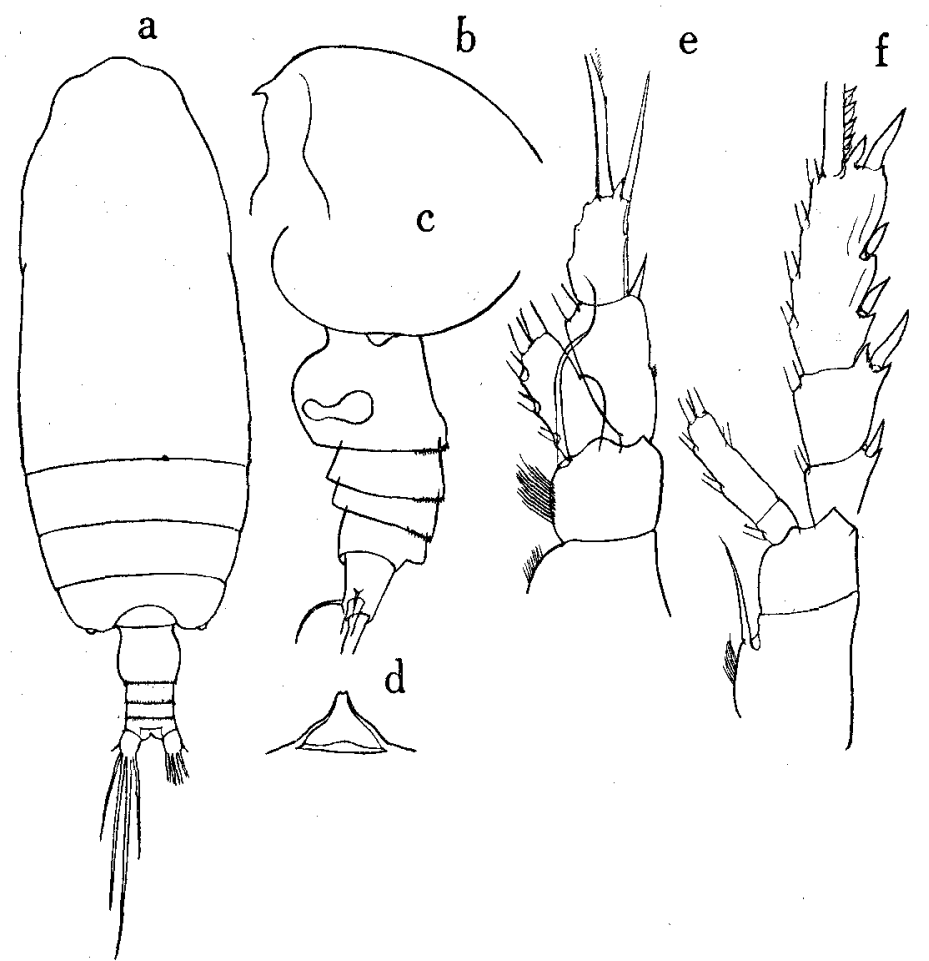

Fig. 39. Gaidius minutus G. O. SARS.

$a$, Female : dorsal aspect; $b$, head, lateral aspect; $c$, last thoracic segment and abdomen, lateral aspect; $d$, rostrum, anterior aspect; $e$, 1st leg; $f$, 2nd leg.

type; terminal spine of exopodite of second leg has 19 teeth (fig. $f$ ). Fourth leg has stiff hairs on inner margin near base of inner marginal spine of first basal 'joint.

Remarks. The present specimen, though slightly differs from SARs' description in having small nodules on lateral corner of last thoracic segment, agrees quite well in other respects with $G$. minutus.

Occurrence. Each an adult female both from Sagami and Suruga, from the deep layers.

Distribution. The species has been recorded from the Atlantic and Indian Oceans. 


\section{Gaidius moderatus sp. nov.}

(Fig. $40, a-p$ )

Female. Length, $3.53 \mathrm{~mm}$ : cephalothorax, $2.78 \mathrm{~mm}$; abdomen, $0.75 \mathrm{~mm}$; so abdomen is contained 3.7-times in the length of cephalothorax. Cephalothorax moderately robust, and oval in dorsal view; the greatest width little shorter than half the length of cephalothorax; head fused with first thoracic segment; last two thoracic segments are fused (fig. $a, b$ ). Lateral spines of last thoracic segment rather slender, and somewhat convergent; the spine does not reach the middle of genital segment (fig. $c$ ). Rostrum triangular and slightly notched at the apex (fig. $f$ ).

Abdomen 4-segmented, segments and furca with proportional lengths $39: 17: 15$ : $12: 17=100$. Genital segment produced below. First three segments are furnished with fine teeth on the distal margin. Furcal rami little longer than wide $(7: 6)$.

First antenna 24-jointed, reaches back to distal margin of genital segment when fully extended; joints are in the following proportional lengths:

$\begin{array}{rrrrrrrrrrrrrrrrr}\text { Joint } & 1 & 2 & 3 & 4 & 5 & 6 & 7 & 8-9 & 10 & 11 & 12 & 13 & 14 & 15 & 16 & 17 \\ & 32 & 45 & 22 & 22 & 26 & 30 & 30 & 48 & 25 & 25 & 25 & 42 & 45 & 48 & 51 & 51 \\ 18 & 19 & 20 & 21 & 22 & 23 & 24 & 25 & & & & & & & & \\ 51 & 67 & 61 & 48 & 67 & 64 & 54 & 22=1000 ; & & & & & & \end{array}$

second to eighth joints have several fine hairs on posterior margin. Second antenna has exopodite 1.2-times as long as endopodite; exopodite robust; inner marginal setae of second joint of endopodite is based each on a small knob; endopodite slender. Mandible as in other members of the genus. First maxilla as shown in the figure; outer lobe has 9 setae; exopodite 11 setae; endopodite 14 setae (fig. $g$ ). Second maxilla as that of $G$. minutus. Maxillipede has a small lamellous process on fourth lobe of first basal joint (fig. $h$ ).

First leg with 2-jointed exopodite; line of fusion between the first and second joints faintly visible on anterior surface (fig. $i$ ). Second leg with 2-jointed enciopodite; terminal spine of exopodite has 19 teeth which are connected with a sort of lamina. Third leg with 3-jointed endopodite; terminal spine of exopodite has 17 teeth. Fourth leg has a row of stiff hairs on inner margin of first basal joint; terminal spine of exopodite has 20 teeth (fig. $k$ ).

Male. Length, $3.19 \mathrm{~mm}$ : cephalothorax, $2.46 \mathrm{~mm}$; abdomen, $0.3 \mathrm{~mm}$; the greatest width of cephalothorax, $1.00 \mathrm{~mm}$. Lateral spines of last thoracic segment, though broken off in the distal part, appears to be fairly long, and reaches the middle of first abdominal segment; it is convergent and moderately wide at the base (fig. $l, o$ ). Rostrum acutely pointed when viewed from the lateral; the apex slightly notched (fig. $m, n$ )

Abdomen 5-segmented, segments and furca with proportional lengths $19: 29: 19$ : $17: 2: 14=100$. Furcal rami about 1.3 -times as long as wide; furcal setae more than 2 -times as long as abdomen and furca taken together. 
First antenna 20-jointed, extends to distal margin of furca; joints are in the following proportional lengths;

$$
\begin{array}{rrrrrrrcccccccc}
\text { Joint } & 1 & 2 & 3 & 4 & 5 & 6 & 7 & 8-9-10 & 11 & 12-13 & 14 & 15 & 16 & 17 \\
& 33 & 36 & 23 & 23 & 26 & 30 & 30 & 69 & 27 & 60 & 33 & 48 & 51 & 54 \\
& 18 & 19 & 20-21 & 22 & 23 & 24-25 & & & & & & \\
58 & 69 & 114 & 75 & 72 & 69=1000 . & & & & & &
\end{array}
$$

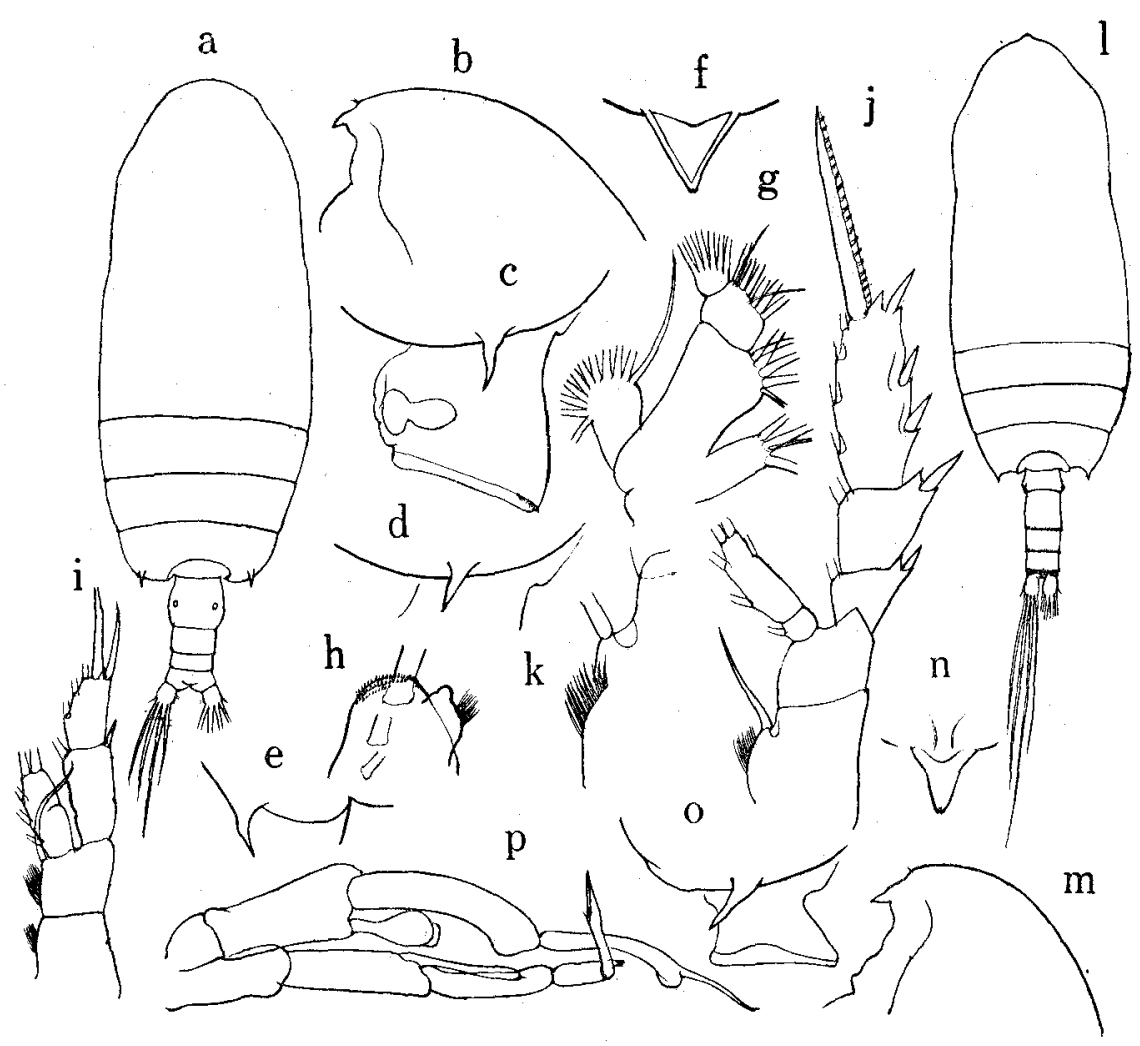

Fig. 40. Gaidius moderatus sp. nov.

$a$, Female: dorsal aspect; $b$, head, lateral aspect; $c$, last thoracic segment and genital segment, lateral aspect; $d$, last thoracic segment, lateral aspect, other specimen; $e$, lateral spine of last thoracic segment, dorsal aspect; $f$, rostrum, anterior aspect; $g$, 1st maxilla; $h$, distal margin of 1st basal joint of maxillipede; $i$. 1st leg; $j$, 2nd leg; $k$, inner margin of 1 st basal joint of 4 th leg; $l$, Male: dorsal aspect; $m$, head, lateral aspect; $n$, rostrum, anterior aspect; $o$, last thoracic segment, lateral aspect; $p$, 5th pair of legs.

Second antenna as those of the foregoing species; first joint of exopodite is furnished with long hairs on the inner margin. Mandible with a wide second basal joint. First maxilla much reduced, and has 7 long setae on first outer lobe, 11 setae on exopodite, 
10 setae on endopodite. Second maxilla and maxillipede as those of the male of foregoing species.

First leg with 2-jointed exopodite; line of fusion between first and second joint faintly visible on the anterior surface. Second leg with 2-jointed endopodite; exopodite broken off. In fourth leg first basal joint is smooth on the inner margin. Fifth pair of legs as those of the foregoing species (fig. $p$ ).

Remarks. Female specimen resembles Gaidius pungens GIEsBRecht, except for the following minute points of difference: posteritor spines of last thoracic segment are shorter in proportion than figured by GIESBRECHT; endopodite of second leg 1jointed in GIESBRECHT's specimen, but the present specimen has 2-jointed endopodite. Posterior spines of last thoracic segment show some variations as shown in the figure.

Occurrence. One female and one male from Sagami, in vertical hauls from $1000-0 \mathrm{~m}$.

(To be continued) 